\title{
Blockchain for Smart Mobility-Literature Review and Future Research Agenda
}

\author{
Erik Karger *, Marvin Jagals and Frederik Ahlemann
}

check for updates

Citation: Karger, E.; Jagals, M.; Ahlemann, F. Blockchain for Smart Mobility—Literature Review and Future Research Agenda. Sustainability 2021, 13, 13268. https://doi.org/10.3390/su132313268

Academic Editor: Manuela

Tvaronaviciene

Received: 21 October 2021

Accepted: 23 November 2021

Published: 30 November 2021

Publisher's Note: MDPI stays neutral with regard to jurisdictional claims in published maps and institutional affiliations.

Copyright: (C) 2021 by the authors Licensee MDPI, Basel, Switzerland. This article is an open access article distributed under the terms and conditions of the Creative Commons Attribution (CC BY) license (https:/ / creativecommons.org/licenses/by/ $4.0 /)$.
Information Systems and Strategic IT Management, University of Duisburg-Essen, 45141 Essen, Germany; marvin.jagals@uni-due.de (M.J.); frederik.ahlemann@uni-due.de (F.A.)

* Correspondence: erik.karger@uni-due.de

\begin{abstract}
Today's cities face numerous challenges due to climate change and urbanization. The concept of a smart city aims to help cities to address these challenges by adapting modern information and communication technology. Smart mobility and transportation form one important aspect of smart cities. Inefficient mobility in cities can lead to problems such as traffic congestion, which results in frustration for residents and a decrease in the quality of life. Against the backdrop of global warming, cities also strive to reduce $\mathrm{CO}_{2}$ emissions, an attempt which requires sustainable and novel mobility concepts. Blockchain is a current technology, said to have huge potential, that is being investigated for application in many facets of smart cities. In the context of smart mobility, blockchain can be used for transactions relating to ridesharing and electric charging, handling of interactions of platoon members, or serving as a foundation for communication between vehicles. Although initial research about this topic exists, it is distributed among different use-cases and applications. This article conducts a systematic literature review to analyze blockchain's role in mobility and transportation in smart cities, and its potential to increase efficiency in these areas. With this review, we aim to consolidate and summarize the current knowledge about this topic. As a first result, we present the findings from our literature review, which can be divided into five categories of use-cases. We also present a platform for further research about this emerging topic by identifying promising future research avenues. For this purpose, we derive a future research agenda based on our findings.
\end{abstract}

Keywords: blockchain; distributed ledger; smart city; smart mobility; transportation

\section{Introduction}

The environmental and economic impact of global warming is startling and disconcerting. Urban areas are responsible for about $67-76 \%$ of the emission of $\mathrm{CO}_{2}$ and the volume of energy consumed, and thus play a decisive role in terms of environmental impacts $[1,2]$. Simultaneously, 55\% of the worldwide population in 2018 was living in urban areas. By 2050 , this proportion is expected to increase to $68 \%$ [3]. It is estimated that globally, nearly 180,000 people move to cities every day, which equates to more than 65 million people a year [4]. This growing number of citizens makes it difficult for cities to ensure minimum living standards and requires increased resources and energy supplies [5,6]. In addition to increased $\mathrm{CO}_{2}$ and greenhouse gas emissions, problems like traffic jams or waste disposal also need to be addressed by cities [7].

The major environmental and global warming impact of cities makes it necessary to act in environmentally friendly and sustainable ways [8,9]. The concept of transforming urban areas into so-called smart cities arose to address the fundamental economic and ecological issues of the 21st century. In general, a smart city is described as an ideal city, where the quality of life and the quality of services for citizens are improved by combining information and communication technologies (ICT) and new urban infrastructures [8,9]. In addition to improving citizens' quality of life, the developmental process of a city should address enhanced use of renewable resources and reduction in waste volumes by safeguarding the environment. Thus, an eco-sustainable perspective must be at the 
foundation of any city transformation approach. This vision promotes an urban and industrial development, able to address current needs without compromising the capacity of future generations [10]. Generally, the smart city is understood as a complex concept, which integrates numerous characteristics, components, and dimensions [11]. The authors of [12] specified these dimensions in six categories: smart economy, smart people, smart governance, smart environment, smart living, and smart mobility.

Within the latter domain, researchers found evidence that traffic is important to allow flexible movement within cities, but traffic time has a negative impact on individual wellbeing. Prior studies also show a strong positive relationship between traffic time and life satisfaction in cities. Traffic has a measurable negative effect on the life quality of citizens, and commute time plays a significant role in cities and entire countries [13-15]. Therefore, the optimization and improvement of transport, mobility, and logistics in urban areas is a crucial goal of realizing the potential of smart cities [16]. The authors of [17] stress that mobility is critical for regions and cities' intellectual development and growth [17]. The huge problem of traffic congestion requires the development of more sophisticated transportation concepts. Apart from these impacts on citizen's quality of life, traffic also leads to air pollution that can have a negative impact on respiratory health [18]. As one possible solution, several nations are deploying electric vehicles and charging stations to build green transportation networks.

Simultaneously, new technologies like blockchain are developing rapidly. Blockchains excel in the way in which transactions are managed. This management is fully distributed without the necessity of a central broker being involved $[19,20]$. Research on smart cities and blockchain already pointed out the enormous potential of blockchain in the context of smart mobility. For instance, technology can protect individuals' personal mobility information and guard their privacy [21]. Blockchain technology and smart contracts have the potential to facilitate decentralized and transparent power trade between electric cars and charging stations [22]. Due to the blockchain's decentralization, transparency, and immutability it is a fitting technology for deploying a decentralized trust management system in automotive networks [22]. Renewable energy sources could also be supported by traceability and provide information about the kind of energy used to refuel [10]. Additionally, the blockchain has the potential to enable decentralized intelligent transportation systems and decentralized vehicular applications [22].

These first contributions give an idea of the potential inherent in the combination of blockchain and smart mobility. However, research in this area is very fragmented, with a focus on individual fields or application areas. There are currently no comprehensive reviews or studies about blockchain's potential for mobility as a whole. This paper aims to fill this research gap, on the one hand by giving a fundamental overview of the current state of research. On the other hand, we believe that it is essential for a review article to identify research gaps and directions for future research [23]. Our second goal with this article is therefore to identify future fields of research. Given the important role of mobility, we believe our research endeavor is of high importance to consolidate the current research of blockchain's potential for mobility. Based on these contributions, smart city research should be motivated and informed to carry out practical research concerning the application potential of blockchain in the traffic and mobility sectors of a smart city. These targets lead us to the following research questions:

RQ1: How can blockchain be used in the context of smart mobility, and what are the resulting benefits and advantages?

RQ2: What are possible future research enquiries in the field of blockchain-based mobility?

The remainder of this article is structured as follows: The second section gives an overview of blockchain technology, smart cities, and smart mobility. The third section presents the research method that we used. The fourth section presents the results of our literature review. In the fifth section we present opportunities and avenues for future 
research. The second last section summarizes and discusses this review's key findings. Finally, in the last section we offer some concluding comments and remarks.

\section{Foundations}

\subsection{Blockchain}

The concept of blockchain was first described in the whitepaper introducing Bitcoin [19]. The blockchain is a new combination of technologies that already existed before, for example, digital signatures and public-key cryptography [24] and hash functions [25,26]. The idea of Bitcoin was to establish a decentralized payment system in which all participants store a copy of the same ledger, including past transactions and ownerships of particular assets [27]. In a blockchain system, transactions can be processed quickly and without a trusted third party [28]. Transactions made in the blockchain system are stored in blocks which are then validated and added to the prior blocks. The validation process is fully distributed without a controlling authority $[19,20]$. One important characteristic of blockchain systems is their resistance to data modification. Due to the connection of the blocks, transactions in the blockchain that have been validated once can't be altered, changed, or manipulated anymore [29].

Nowadays, the blockchain cannot be seen as one single, uniform technology. Instead, there are thousands of different blockchain projects in development [30]. Therefore, [30] refer to "blockchains" or "blockchain technologies" instead of speaking about one single blockchain technology. Blockchains can differ in the ways in which the consensus in the network is achieved, what kind of currency is used, and how security and privacy are achieved [30]. Two criteria that are also often used to classify blockchains are access to transactions and access to the validation of transactions [31,32]. In public permissionless blockchains, all participants can read, submit, and validate transactions.

In contrast, hybrid blockchains allow the reading and submitting of transactions for all network nodes. However, only authorized nodes can validate the new transactions. Lastly, private blockchains are the most restricted systems and allow only authorized nodes to read, submit, and validate transactions. Table 1 gives an overview of the resulting three types of blockchain systems.

Table 1. Classification of Blockchain Systems (based on [31,32]).

\begin{tabular}{|c|c|c|c|}
\hline \multicolumn{4}{|c|}{ Access to Transaction Validation } \\
\hline & & Permissioned & Permissionless \\
\hline \multirow[t]{2}{*}{$\begin{array}{l}\text { Access to } \\
\text { transactions }\end{array}$} & Public & $\begin{array}{l}\text { All nodes can read and submit } \\
\text { transactions. Only authorized } \\
\text { nodes can validate transactions. }\end{array}$ & $\begin{array}{c}\text { Every node in the network } \\
\text { can both read, submit, and } \\
\text { validate transactions }\end{array}$ \\
\hline & Private & $\begin{array}{l}\text { Only authorized nodes can read, } \\
\text { submit, and validate transactions }\end{array}$ & Not possible \\
\hline
\end{tabular}

Since the blockchain first emerged, its potential has been investigated for many different domains and use-cases. Examples include, but are not limited to, healthcare [33], the improvement of supply chains [34,35], direct democracy [36], and e-commerce [37]. Next to use-cases for specific industries and applications, there is an increasing convergence of blockchain with other technologies; for instance, the blockchain is used in combination with the internet of things [38], artificial intelligence (AI) [39], and big data [40].

Smart contracts are another term often used in direct connection with the blockchain. Smart contracts, first proposed by Nick Szabo, are computerized protocols that automatically enforce contractual clauses when certain conditions are met $[28,41]$. Smart contracts allow payments and the transfer of currencies or other assets to be executed and automated. An example of an application is a payment to a supplier as soon as a shipment is delivered. Similarly, a company could use a blockchain with smart contracts to signal that a particular item has been received. If the product has GPS functionality, the evaluation of the location 
could also automatically trigger a payment [42]. The utilization of smart contracts is investigated for a number of different applications, like the sharing economy [43], IoT [44], or the public sector $[45,46]$.

Despite its advantages and many potential use-cases, there are also disadvantages related to blockchain. One dark side of cryptocurrencies, especially the bitcoin, is that it is often used for criminal purposes and money laundering. Cryptocurrencies are attractive to criminals for a variety of reasons: The anonymity, the ease of use, and the fact that cryptocurrencies' use is independent of borders or legislation make it suitable for criminal purposes [47-49]. Another problem often mentioned in relation to bitcoin is its high level of energy consumption. In PoW networks, the so-called miners must find a specific hash value that meets specific requirements. The amount of energy consumed for that purpose has reached an immense scale [50], comparable to the consumption of countries like Belgium, Kazakhstan, or the Netherlands. Although this disadvantage relates to blockchain networks based on PoW, like bitcoin, it does not apply to all forms of blockchain systems in general [27]. For instance, in systems using the proof of stake (PoS) or delegated proof of stake (DPoS) consensus algorithms, energy consumption is greatly reduced. Furthermore, other blockchain implementations exist that do not require a mining process at all [50].

\subsection{Smart City and Smart Mobility}

The globe is witnessing a paradigm change to 'smartness' in cities, management, and sustainability, leading to the widespread popularity of the notion of smart cities [51]. Over the last several years, the term 'smart city' has gained popularity [52]. Smart cities as a concept have their roots in the 1980s, when ideas appeared that focused on cities' efficiency and competitiveness and the ways in which cities can be managed easily [52,53]. The authors of [12] published a well-known approach to the structure dimensions of smart city initiatives in six main parts. According to these dimensions, the fundamental smart city components are smart economy, smart people, smart governance, smart environment, smart living, and smart mobility. Comprehensive surveys, for example [54] or [9], give a holistic overview of different topics like research goals, definitions, application domains, technologies, and architectures. Other topics investigated in the context of smart cities are, for instance, software architectures [55], trace analysis [56], business models [57], and entrepreneurship [5]. Despite being around for at least three decades, the smart city concept consists of blurred definitions which are not consistent and appear in many different ways [58]. Given the multifaceted character of smart cities, we follow [59] and stick to the definition of [60], since it has gained widespread use and covers all aspects of a smart city that are relevant for this article's results: "[ . . ] a city [is] smart when investments in human and social capital and traditional (transport) and modern (ICT) communication infrastructure fuel sustainable economic growth and a high quality of life, with a wise management of natural resources, through participatory governance" [60].

One of the major targets of smart city initiatives is alleviating the existing congestion conditions in most metropolitan regions. The solutions vary from self-driving cars that eliminate automobile ownership to sensor deployment in vital urban infrastructure [61]. One of the dimensions of a smart city is referred to as smart mobility. According to [17], smart mobility is a buzzword for combining different technologies and approaches. The overarching goal of smart mobility is to make the transportation of people and goods more sustainable and efficient $[8,17,62]$. Intelligent transportation systems (ITS) have emerged with the goal to apply several advantages to mobility, like improving travel security and increasing the performance of transportation systems [63]. In addition, ITS enables smart vehicles to communicate with each other and access the internet [22]. Smart mobility is also a critical component of the urban environment's functioning. However, transportation presents several significant issues and negative consequences for citizens' quality of life, such as pollution or longer travelling times. Smart mobility aims to assist cities in reducing traffic, accident rates, and urban footprint. Furthermore, smart mobility concepts can help 
to improve air quality and thus assist cities in achieving sustainable growth [64], since mobility and transportation are major drivers of climate change [62].

\section{Method}

Our research goal with this article is to assess the current state of research dealing with the role and potential of blockchain for smart mobility. Therefore, we conducted a systematic literature review to identify all relevant literature within this field. A systematic literature review is a distinct and organized method for the goal and purpose of finding, assessing, and analyzing literature $[65,66]$. We followed the guidelines for performing systematic literature reviews provided by [67] to secure our review's quality and structure.

We conducted the initial search of the literature in the Web of Science (WoS) and Scopus databases. WoS covers scientific publications from more than 12,000 journals by 3300 publishers and also contains a reference index of over 1 billion cited references [68]. Scopus includes an even larger number of journals than WoS [23] and incorporates searches in patent databases [69]. This last point makes it especially suitable for research in technical and innovative areas like blockchain. Next to WoS and Scopus, we did additional searches in six smaller scientific databases to ensure that we covered all relevant outlets and didn't exclude any relevant publications. These databases were the ACM Digital Library, the AIS eLibrary, IEEE Xplore, ProQuest, SageJournals, and Science Direct. As 2008 was the year when the idea of blockchain first emerged [19], we limited our search to articles published subsequent to 2008. We applied the following search string to the selected databases and searched in title, abstract, and keywords:

(("blockchain” OR "block chain" OR "bitcoin" OR "ethereum" OR "distributed ledger" OR “DLT" OR "smart contract") AND ("mobility" OR "traffic" OR "transportation" OR "logistics"))

The search string's first main part covers the technical terms related to blockchain. Apart from "blockchain" and "block chain," we also added other related terms. First, "bitcoin" and "ethereum" were added, as these are the names of the most prominent blockchain-based currencies [70,71]. Although Bitcoin and Ethereum are not directly related to the use-case of smart mobility, we decided to include these terms in our search string for a number of reasons. First, in early research about blockchain, bitcoin as the most prominent blockchain application was often considered. Therefore, to also cover early blockchain research, we added bitcoin. Furthermore, Ethereum is an important platform and blockchain ecosystem that is often used as the blockchain technology for other projects [72]. Therefore, we considered it necessary to include "ethereum" as it might be used as a basis for mobility-related solutions. We also included "distributed ledger", since blockchain is a distributed ledger technology (DLT) and many authors do not differentiate between these two terms. Additionally, we added smart contracts, as these are a crucial part of many blockchain-based applications. The search string's second part comprises different mobility-related terms; apart from "mobility", we also searched for "traffic", "transportation" and "logistics".

Figure 1 summarizes the research process, the different elimination criteria, and the respective number of publications that resulted. The search was executed on 10 February, 2021, and led to 1238 initial results after duplicates were eliminated. After receiving the initial literature sample, we decided on several inclusion and exclusion criteria to narrow down the number of papers. First, we only included articles dealing with the usage, application, or implementation of blockchain in the context of mobility and transportation. We excluded all articles that investigated other topics or blockchain and mobility isolated. 


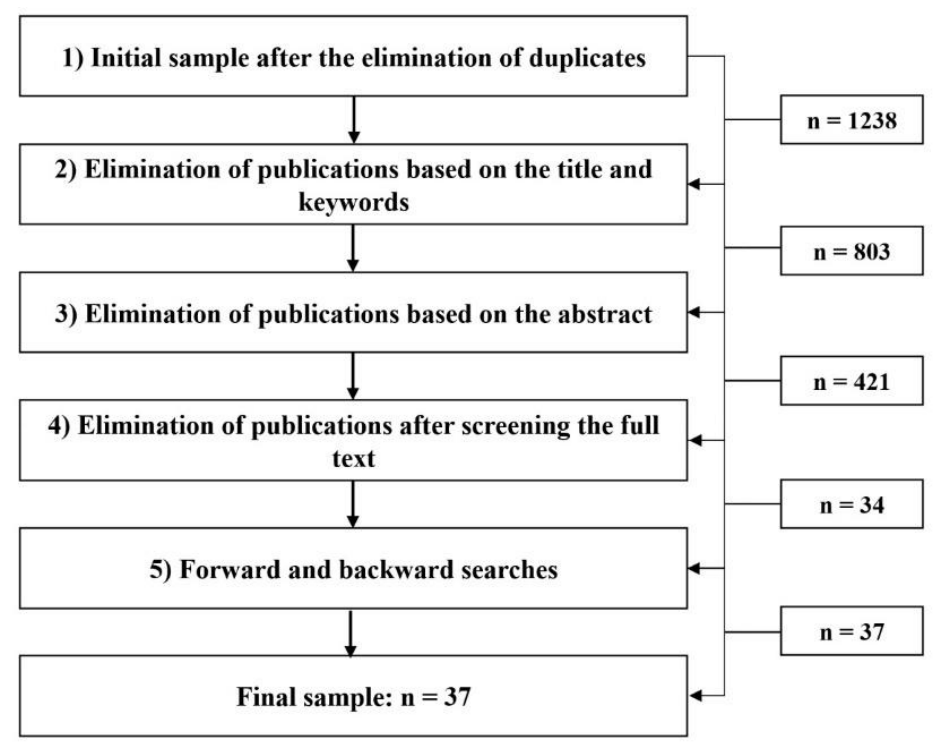

Figure 1. Overview of elimination criteria and publication numbers (own representation).

We also focused on literature with an academic nature published in peer-reviewed journals and conferences. Non-peer-reviewed articles were excluded from our initial sample, as were white papers or practitioner reports. Furthermore, non-English articles were not taken into consideration.

Following these criteria, the initial sample was independently reviewed by the first two authors. The first step was to exclude the remaining articles based on their title and keywords with these criteria set. This led to an elimination of 435 articles. In the next iteration, the remaining articles' abstracts were investigated, leading to a further 382 eliminations. We investigated the full text of the remaining 421 articles and eliminated 387 more. We did forward and backward searches in the articles that remained and were able to find three additional papers. This led to a final sample of 37 articles which we then analyzed. Table 2 shows the final sample of publications that we investigated.

Table 2. Overview of this Article's Final Sample of Literature.

\begin{tabular}{ccc}
\hline Year & Authors & Title \\
\hline 2016 & $\begin{array}{c}\text { Yuan and Wang } \\
\text { Leiding et al. } \\
\text { Sharma et al. }\end{array}$ & $\begin{array}{c}\text { Towards blockchain-based intelligent transportation systems } \\
\text { Self-managed and blockchain-based vehicular ad-hoc networks } \\
\text { Block-VN: A Distributed Blockchain Based Vehicular Network } \\
\text { Architecture in Smart City }\end{array}$ \\
2017 & Dubois et al. & An App-based Algorithmic Approach for Harvesting Local and \\
2017 & Kang et al. & Renewable Energy using Electric Vehicles
\end{tabular}


Table 2. Cont.

\begin{tabular}{|c|c|c|}
\hline Year & Authors & Title \\
\hline 2019 & Baza et al. & $\begin{array}{c}\text { B-Ride: Ride Sharing with Privacy-preservation, Trust and Fair } \\
\text { Payment atop Public Blockchain }\end{array}$ \\
\hline 2019 & Kim & Impacts of Mobility on Performance of Blockchain in VANET \\
\hline 2019 & Khanji and Assaf & $\begin{array}{c}\text { Boosting Ridesharing Efficiency Through Blockchain: GreenRide } \\
\text { Application Case Study }\end{array}$ \\
\hline 2019 & Nguyen et al. & Blockchain-Based Mobility-as-a-Service \\
\hline 2019 & Semenko and Saucez & Distributed Privacy Preserving Platform for Ridesharing Services \\
\hline 2019 & Valaštin et al. & Blockchain Based Car-Sharing Platform \\
\hline 2019 & Yang et al. & $\begin{array}{c}\text { Blockchain-Based Decentralized Trust Management in } \\
\text { Vehicular Networks }\end{array}$ \\
\hline 2019 & Ying et al. & $\begin{array}{c}\text { BAVPM: Practical Autonomous Vehicle Platoon Management } \\
\text { Supported by Blockchain Technique }\end{array}$ \\
\hline 2019 & Zhang and Chen & $\begin{array}{c}\text { Data Security Sharing and Storage Based on a Consortium } \\
\text { Blockchain in a Vehicular Ad-hoc Network }\end{array}$ \\
\hline 2019 & Zhang and Wang & Data-Driven Intelligent Transportation Systems: A Survey \\
\hline 2019 & Zhang et al. & Blockchain Based Secure Package Delivery via Ridesharing \\
\hline 2020 & Abubaker et al. & $\begin{array}{c}\text { Decentralized Mechanism for Hiring the Smart Autonomous } \\
\text { Vehicles Using Blockchain }\end{array}$ \\
\hline 2020 & Aujla et al. & $\begin{array}{c}\text { BloCkEd: Blockchain-Based Secure Data Processing Framework in } \\
\text { Edge Envisioned V2X Environment }\end{array}$ \\
\hline 2020 & Chen et al. & $\begin{array}{l}\text { Smart-Contract-Based Economical Platooning in } \\
\text { Blockchain-Enabled Urban Internet of Vehicles }\end{array}$ \\
\hline 2020 & George et al. & $\begin{array}{c}\text { Secure Identity Management Framework for Vehicular Ad-hoc } \\
\text { Network using Blockchain }\end{array}$ \\
\hline 2020 & Gudymenko et al. & $\begin{array}{c}\text { Privacy-Preserving Blockchain-Based Systems for Car Sharing } \\
\text { Leveraging Zero-Knowledge Protocols }\end{array}$ \\
\hline 2020 & Ji et al. & A Blockchain-Based Vehicle Platoon Leader Updating Scheme \\
\hline 2020 & Khelifi et al. & $\begin{array}{c}\text { A blockchain-based architecture for secure vehicular Named } \\
\text { Data Networks }\end{array}$ \\
\hline 2020 & Malik et al. & $\begin{array}{l}\text { Vehicular networks with security and trust management solutions: } \\
\text { proposed secured message exchange via blockchain technology }\end{array}$ \\
\hline 2020 & Palanisamy et al. & $\begin{array}{c}\text { Decentralized Social Media Applications as a Service: a } \\
\text { Car-Sharing Perspective }\end{array}$ \\
\hline 2020 & Raja et al. & $\begin{array}{c}\text { AI-Powered Blockchain - A Decentralized Secure Multiparty } \\
\text { Computation Protocol for IoV }\end{array}$ \\
\hline 2020 & Ying et al. & $\begin{array}{l}\text { BEHT: Blockchain-Based Efficient Highway Toll Paradigm for } \\
\text { Opportunistic Autonomous Vehicle Platoon }\end{array}$ \\
\hline 2020 & Zhou et al. & $\begin{array}{l}\text { A Decentralized Car-Sharing Control Scheme Based on Smart } \\
\text { Contract in Internet-of-Vehicles }\end{array}$ \\
\hline 2021 & Kudva et al. & $\begin{array}{c}\text { Towards secure and practical consensus for blockchain } \\
\text { based VANET }\end{array}$ \\
\hline 2021 & Saurabh et al. & The ARTICONF Approach to Decentralized Car-Sharing \\
\hline
\end{tabular}

\section{Review Results}

The research dealing with blockchain in smart mobility has increased tremendously over the last few years. The first identified articles in this area were proposed in $2016[73,74]$. They deal with proposals on how to secure and enhance the architecture of ITS and vehicular ad-hoc networks. After 2016, the number of annual publications within the field of blockchain and smart mobility increased steadily. After only two articles in 2016, we identified four articles from 2017 and six articles published in 2018. In 2019, 11 articles were published, followed by 12 publications in 2020 . The low number of identified articles in 2021 is due to the fact that we undertook our literature search at the beginning of the year.

The distribution of publications among the individual outlets can be considered very heterogeneous. So far, there are no conferences or journals that focus exclusively on the topic. Most publications are based in the disciplines of computer science, vehicular technology, and engineering. The distribution between conference and journal publications is equal, with 18 journal and 18 conference articles. Furthermore, one book chapter was identified through a backward search. Table 3 gives an overview of the number of articles for each outlet. Here, IEEE Access leads with a total of four articles, followed by the IEEE Internet of Things Journal, the IEEE Symposium on Computers and Communications, and the IEEE Transactions on Industrial Informatics with two publications, each. 
Table 3. Overview of the Publication Numbers for Every Outlet.

\begin{tabular}{|c|c|}
\hline Outlet & \# \\
\hline IEEE Access & 4 \\
\hline IEEE Internet of Things Journal & 2 \\
\hline IEEE Symposium on Computers and Communications & 2 \\
\hline IEEE Transactions on Industrial Informatics & 2 \\
\hline ACM International Joint Conference & 1 \\
\hline Blockchain: Research and Applications & 1 \\
\hline Computer Science-Research and Development & 1 \\
\hline Computers \& Electrical Engineering & 1 \\
\hline IEEE Conference on Computer Communications Workshops (INFOCOM) & 1 \\
\hline IEEE International Conference on Communications & 1 \\
\hline $\begin{array}{c}\text { IEEE International Conference on Decentralized Applications and } \\
\text { Infrastructures (DAPPS) }\end{array}$ & 1 \\
\hline IEEE Pacific Rim International Symposium on Dependable Computing & 1 \\
\hline IEEE Transactions on Intelligent Transportation Systems & 1 \\
\hline IEEE Transactions on Network Science and Engineering & 1 \\
\hline IEEE Transactions on Vehicular Technology & 1 \\
\hline IEEE Vehicular Technology Conference & 1 \\
\hline Information Sciences & 1 \\
\hline International Conference on Agents and Artificial Intelligence & 1 \\
\hline International Conference on Computer Communication and Networks (ICCCN) & 1 \\
\hline International Conference on Information and Communication Systems (ICICS) & 1 \\
\hline International Conference on Intelligent Transportation Engineering & 1 \\
\hline International Conference on Intelligent Transportation Systems & 1 \\
\hline International Conference on Wireless Communications and Signal Processing (WCSP) & 1 \\
\hline International Symposium ELMAR & 1 \\
\hline iThings/GreenCom/CPSCom/SmartData & 1 \\
\hline Journal of Information Processing Systems & 1 \\
\hline Lecture Notes in Networks and Systems & 1 \\
\hline Security, Privacy, and Anonymity in Computation, Communication, and Storage & 1 \\
\hline TrustCom/BigDataSE & 1 \\
\hline Wireless Communications and Mobile Computing & 1 \\
\hline Wireless Networks & 1 \\
\hline
\end{tabular}

The use-cases dealing with blockchain in the context of smart mobilities can be divided into five categories. Much research deals with ITS and vehicular ad-hoc networks (VANETs). ITS and VANETs often form the technical foundation for many future mobility solutions. The blockchain promises several benefits, like security against malicious vehicles and safe sharing of information between vehicles. This communication between vehicles, that we refer to in the following as vehicular communication, is an important field that we deal with in the second subsection. Vehicular communication is closely related to VANETs, and often takes place through a VANET. However, given the relevance of this area, we considered it necessary to deal with this topic in its own subsection.

Due to the increasing number of electric vehicles in use, the process of and the infrastructure for electric charging are important issues for cities. Therefore, we outline the use-case of blockchain-based electric charging after the subsection dealing with vehicular communication. Subsequent to that, we investigate blockchain-based ridesharing (BCbRS). Ridesharing is a key factor for cities wishing to reduce the number of vehicles and achieve efficient traffic management. Next to the use-case of ITS and VANETs, ridesharing is the smart mobility application addressed by most authors. Finally, we investigate the potential for platoons, which are convoys of trucks moving together. We outline this use-case in the last subsection. Table 4 gives an overview of the different applications and the respective publications. 
Table 4. Overview of the Publication's Numbers for Every Outlet.

\begin{tabular}{cc}
\hline Thematic Area & Publications \\
\hline \multirow{3}{*}{ Intelligent Transportation Systems } & {$[73-75]$} \\
& {$[76-78]$} \\
Vehicular Communication & {$[79-81]$} \\
Electric Charging & {$[82-84]$} \\
& {$[76,87]$} \\
\hline \multirow{2}{*}{ Ridesharing } & {$[88,89]$} \\
\hline & {$[90,91]$} \\
& {$[92,93]$} \\
\hline \multirow{2}{*}{ Platooning } & {$[86,94,95]$} \\
& {$[96-98]$} \\
& {$[99-101]$} \\
& {$[102-104]$} \\
\hline
\end{tabular}

\subsection{Intelligent Transportation Systems}

The authors of [74] and [76] discuss the usefulness of a blockchain as the foundation for an ITS. These authors see the need to develop an architecture that is decentralized, secured, and trusted to guarantee the ITS ecosystem's stability, profitability, and effectiveness. The authors of [76] focus on secure vehicular communication, which will be outlined in the following subsection. The authors of [74] take a broader perspective and propose a blockchain-based ITS model. They believe that the advantages of blockchain models like decentralization, security, and trust make it highly suitable for such a purpose. The model proposed in [74] consists of seven different layers: The physical layer contains different physical objects like cars, traffic lights, or devices; the data layer stores the different blocks of the blockchain and provides the underlying techniques of the blockchain, like hash algorithms and asymmetric encryption; and the forwarding and verification of the data and establishment of the distributed network are ensured in the network layer. The consensus layer is composed of possible consensus mechanisms and ensures the consensus of the whole network. The incentive layer incorporates economic rewards in blockchains and specifies their output and allocation mechanisms to motivate the network participants to proceed with mining and verification of transactions. The contract layer serves as the foundation for, among other things, smart contracts, which are useful in ITS to control and manage physical and digital assets and make them programmable. Lastly, the application layer illustrates the resulting applications, like ridesharing, logistics, and asset management [74]. Figure 2 illustrates the different layers of the ITS architecture proposed by [74]. 


\begin{tabular}{|c|c|}
\hline & Application Layer \\
\hline & Contract Layer \\
\hline & Incentive Layer \\
\hline & Consensus Layer \\
\hline & Network Layer \\
\hline & Data Layer \\
\hline ) & Physical Layer \\
\hline
\end{tabular}

Figure 2. Layers of a blockchain-based ITS (own representation based on [73]).

Vehicular networks, also referred to as vehicular ad-hoc networks (VANETs), are a component of an ITS and can be defined as a self-organized network in that vehicles can communicate with each other (vehicle-to-vehicle, V2V) and with the infrastructure (vehicleto-Infrastructure, V2I) [109]. Such a VANET allows vehicles to share information about weather conditions or road defects, for example, thus increasing the security and efficiency of the traffic [110]. The communication is enabled by a communication protocol called dedicated short-range communication (DSRC). With wireless communication devices called on-board units (OBUs), the autonomous vehicles can communicate with each other and road side units (RSUs) [110]. A trusted authority (TA) is another component responsible for managing the whole system [109]. Figure 3 gives an overview and illustration of a VANET. However, to guarantee secure communication, several issues concerning privacy and security need to be addressed [110]. Furthermore, VANETs are vulnerable to many possible attacks [111]. Security in VANETs is crucial, as attacks might directly involve or endanger human lives. With vehicles becoming increasingly autonomous, the need to securely exchange data becomes important. Here, blockchain-based smart contracts can serve as a foundation for a variety of intelligent transportation scenarios. Next to ITS, VANETs therefore present another blockchain case discussed herein [72,75,105,107].

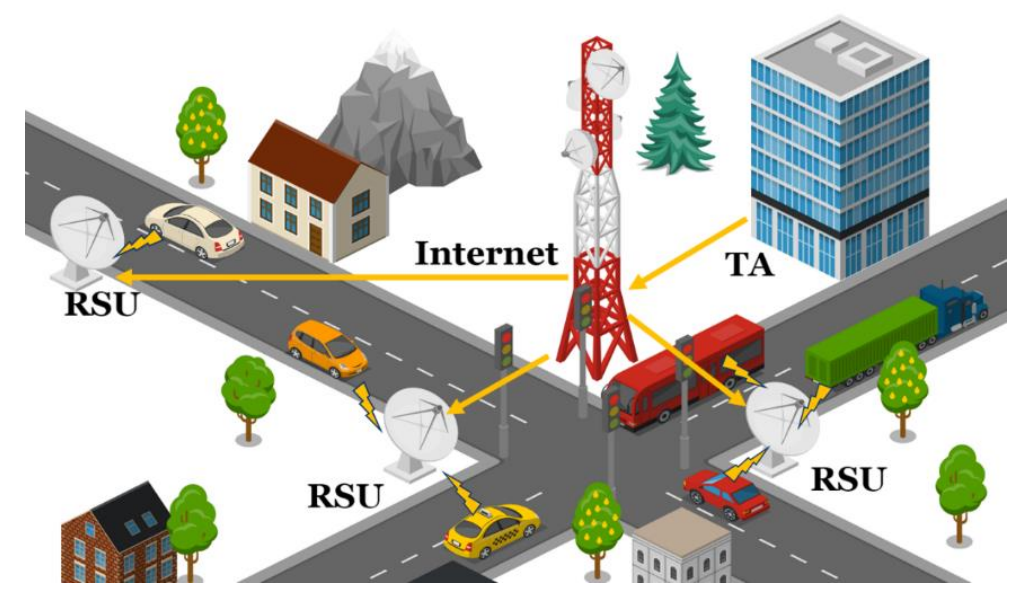

Figure 3. Exemplary representation of a VANET (own representation).

The authors of [75] believe that the blockchain can serve as the foundation on which to build such an autonomous transportation system that is distributed, intelligent, and secure. They propose a blockchain-based architecture for a distributed vehicular network 
suitable for ridesharing purposes (see below). Although the authors outline several design principles, their work remains conceptual and does not include precise technical details for realization. Other authors propose blockchain-based VANETs that are based on already existing blockchain systems. References [73] and [84] propose the idea of a self-managed VANET based on the Ethereum blockchain. Ethereum is a blockchain-based platform that enables the creation of smart contracts due to its programming language. The direct integration of smart contracts in the Ethereum-based VANET enables completely new self-managed and automated applications. The authors, for example, mention vehicle insurance applications or the automized payment of vehicle taxes [73]. Reference [84] furthermore recommends the supplementary use of AI to support the use of blockchain in the VANET context. The authors believe AI can be used to make smart contracts intelligent, to verify transactions, and to reduce the blockchain's energy consumption [84]. This is in line with recent research in information systems and computer science that propose the use of AI for intelligent smart contracts [112,113], to predict a blockchain's transaction confirmation time [114], or even for new consensus algorithms based on AI, called Proof of Artificial Intelligence (PoAI) [115].

Despite blockchain's vast potential for VANETs, some authors are critical of how a blockchain-based VANET's consensus can be achieved. One main reason is that, in a VANET, the network's nodes are mobile and moving [116]. Some authors [78,116] therefore conclude that using PoW cannot be used in the context of peer-to-peer VANETs to achieve a full blockchain validation. In addition, [85] addresses the various deficiencies regarding efficiency, scalability, and fairness that consensus protocols like PoW and PoS suffer from. As a countermeasure against these shortcomings, they propose a new consensus algorithm called Proof of Driving (PoD). The authors of [85] conducted an experimental analysis and showed that their approach successfully selects suitable mining nodes and secures the network against infiltration attacks. Instead of Ethereum, the authors of [87] used a permissioned blockchain technology called Hyperledger Fabric. Although many different consensus algorithms can be used, [87] recommend the default algorithm for consensus in Hyperledger Fabric, called SOLO. Only one network's node is selected within SOLO for ordering the blocks and updating the blockchain network's ledgers [87]. The authors of [80], on the other hand, recommend the use of the practical Byzantine Fault Tolerance (PBFT) consensus algorithm [117]. PBFT is supposed to have several advantages, including increasing the transaction confirmation speed and solving data loss and data delay issues. Through experiment, the authors showed that their approach made the confirmation time of new blocks six times faster than traditional blockchain systems using PoW [80].

Further works within the field of blockchain-based VANETs have been proposed by $[77,79,81,83]$ and [82]. The authors of [77] propose a new mechanism for trust management in VANETs. The authors state that trust and security are important issues in VANETs and that forged messages and tracking attacks need to be prevented. With BARS, they present a blockchain-based anonymous reputation system to reduce the spread of forged messages and to motivate vehicles to divulge misbehaving acts [77]. The authors of [79] propose a blockchain-based traffic signal control mechanism. Their approach can intelligently switch traffic lights and allocate the green light duration time. The authors of [83] demonstrate and experimentally evaluate a new system for trust management in VANETs that consists of two different phases. Finally, reference [82] focuses on named data networks (NDN) in a vehicular context. With their approach, the authors aim to ensure secure and anonymous data forwarding.

\subsection{Vehicular Communication}

Next to the fundamental architecture of VANETs and ITSs, vehicular communication is another aspect in the context of smart mobility where the blockchain might be able to bring improvement. The authors of [76] focus on vehicular communication systems (VCS), which build the platform for the communication in an ITS, both among vehicles and between vehicles and the infrastructure [76]. They also argue that, despite developments 
over the last years, VCSs still have to deal with problems and issues concerning security and key management $[76,118,119]$. Therefore, the authors propose a blockchain-based key-management scheme to share the keys for communication between different devices or vehicles securely [76]. The authors of [88] propose an approach for decentralized trust management in vehicular networks based on a blockchain. In a vehicular network, there is a high level of fluctuation among the participants with the result that the different members don't know and, therefore, can't trust each other. This creates the danger of malicious vehicles being part of the network and sharing incorrect and unreliable information. Hence, the authors stress that it is complicated for vehicles to evaluate the trustworthiness and credibility of received messages in a vehicular network [88]. With the help of the blockchain-based approach of [88], network participants can obtain the trust values of other participants in the network and, based on this, evaluate the trustworthiness of received messages. Apart from enabling a secure and trustworthy communication environment, motivating the participants of a vehicular network to share information is another challenging task [89]. To address this issue, the authors of [89] propose CreditCoin, which is able to motivate vehicles in a network to share traffic information by simultaneously ensuring privacy.

\subsection{Electric Charging}

To increase sustainability and decrease the emissions caused by traffic, cities increasingly focus on electric vehicles (EVs) and the corresponding infrastructure. To ensure the mobility of electric vehicles, charging stations and the necessary infrastructure is important [22]. The question of how the blockchain can benefit electric vehicles and their charging process has already been addressed by research for different specific use-cases. The authors of [90] propose an app-based solution to optimize the charging of electric vehicles with energy from distributed, renewable energy sources. According to the authors, a blockchain in combination with smart contracts could be a good technology to avoid the involvement of a third party and, thus, to create the autonomy and dynamism of the approach [90]. The authors of [91] present a solution called PETCON, which makes it possible for Plug-in Hybrid Electric Vehicles (PHEVs) to buy and sell energy from and to each other in smart grids. This enables the charging and discharging of PHEVs by simultaneously ensuring security and transparency without the need for a trusted third party [91].

Two elaborated approaches from 2018 have been proposed in [93] and [92]. The authors of [93] state that the increasing number of electric vehicles requires a dense and widespread infrastructure for charging. This offers the opportunity for a liberalized market with many different providers of energy and charging stations. Although such a market with different tariff options might lead to many advantages for customers, privacy issues can occur due to the tracking of vehicles. The blockchain-based approach recommended in [93] enables electric vehicles to signal their need for charging energy and charging stations in the vicinity to send auction-like offers to the respective vehicle. This guarantees a high level of transparency about the prices in a region and, at the same time, a high level of privacy [93]. The authors of [92] propose a new security model based on a blockchain and smart contracts to realize secure energy trading between electric vehicles and charging piles. Their approach divides the charging process into four stages, beginning with registration, followed by scheduling, authentication, and the charging phase [92]. In the concepts proposed in both [92] and [93], different charging stations can send offers to demanding vehicles. The question of the criteria according to which a vehicle chooses a specific charging station is addressed in [92]. They propose four different scheduling strategies, which choose a charging station based on the distance, the time costs, the comprehensive costs (consisting of time and consumption costs), and the waiting time. Due to experiments, the authors showed that the choice based on the shortest path is the best in terms of consumption costs for the electric vehicle [92]. 


\subsection{Ridesharing}

Ridesharing is one of the use cases in the field of smart mobilities for which blockchain is most often discussed. The general concept of sharing can be very valuable for cities, as this can reduce the total amount of waste [120]. Additionally, in the context of transportation, sharing can be valuable as it can help drivers to reduce or share their fuel costs, and it can be cheaper compared to other means of transportation [94]. Ridesharing can have several benefits, especially in large cities with congestion or traffic jams [96]. However, there are some concerns relating to ridesharing, e.g., the leakage or usage of personal data [98]. Furthermore, most of the existing ridesharing services or platforms are managed by a centralized third party, resulting in one single point of failure [95]. Using the blockchain in the context of ridesharing is in line with prior research that investigates blockchain's role in the sharing economy [121,122]. The authors propose solutions for ride and car-sharing that suggest many benefits for drivers, riders, and cities. The suggested proposals differ not only in terms of the assumed benefits, but also in the underlying blockchain technology. Table 5 summarizes the identified publications that propose blockchain solutions for ridesharing and their proposed blockchain system.

Table 5. Overview of the Blockchain-Based Ridesharing Solutions and Their Underlying Blockchain System.

\begin{tabular}{ccc}
\hline Year & Source & Blockchain System \\
\hline 2018 & {$[94]$} & Ethereum \\
2019 & {$[95]$} & Ethereum \\
2019 & {$[96]$} & Ethereum \\
2019 & {$[98]$} & Own Development/Not specified \\
2019 & {$[99]$} & Ethereum \\
2019 & {$[100]$} & Own Development/Not specified \\
2020 & {$[101]$} & Ethereum \\
2020 & {$[102]$} & Ethereum/Hyperledger \\
2020 & {$[103]$} & ARTICONF/Hyperledger \\
2020 & {$[104]$} & Ethereum \\
2021 & {$[86]$} & ARTICONF/Hyperledger \\
\hline
\end{tabular}

In 2018 Chang and Chang proposed the earliest approach to blockchain-based ridesharing. The authors see problems in previous ridesharing applications and believe blockchain can provide several advantages in this context [94]. Their approach uses the Ethereum blockchain and several smart contracts for different purposes. A so-called summary contract includes the necessary information to identify users in the system. Passengers making a request enter their conditions, like required date and time, into a passenger smart contract (PSC). The drivers in the system do likewise and insert dates like available time, date, available areas, and vehicle capacity in a driver smart contract (DSC). The system then automatically arranges matches between passengers and drivers based on the PSCs and DSCs.

In 2019, the research on blockchain-based ride and car-sharing saw increased growth with several new approaches published [95-100]. According to The authors of [98], a distributed platform could help to counteract many existing issues in ridesharing platforms. In their approach, the blockchain is used to control access to the data, log events, and avoid parties acting against the rules of the respective network or platform. In addition, the blockchain functions as the marketplace calculating the prices [98]. Another approach stems from [95], where the authors propose a ridesharing approach based on the public blockchain Ethereum. This solution can solve several problems, like preventing malicious users from submitting multiple ride requests without committing to them. The first experimental tests by the authors indicate that this approach would be applicable on top of other existing blockchains [95]. The authors of [96] propose a blockchain-based ridesharing application called GreenRide. The users are motivated to use GreenRide by 
getting rewarded with a special token mapped to the amount of carbon saved through ridesharing [96]. One other interesting use case is proposed in [100] where the authors present the idea of secure package delivery with the help of blockchain-based ridesharing, a delivery service they see as a promising application to improve vehicle occupancy and save travel costs. However, in today's ridesharing platforms vehicles have to share private information to a centralized, controlling instance frequently. This leads to the danger of possible data leakages or tampering. Arguing that blockchain's decentralized nature is able to counteract these difficulties, The authors of [100] therefore propose a blockchain-based solution. To increase their solution's efficiency and transaction throughput, the authors recommend using a PBFT-based consensus algorithm. Based on security analysis and conducted simulations, they conclude that their approach can lead to a low confirmation delay and a high transaction throughput.

Newer approaches are proposed in [101-104], and [86]. The authors of [101] recommend an Ethereum-based ridesharing solution with a PoW consensus algorithm. Their approach aims at autonomous vehicles and enables a secure and reliable matching between these and the customers requiring a ride. The authors of [102] propose two different proofs-of-concept for blockchain-based ridesharing, one based on Ethereum, the other on Hyperledger Indy. The authors conclude that Hyperledger Indy might be more flexible and efficient in many use-cases. However, Ethereum might be the better design choice when compatibility with other existing blockchain ecosystems is necessary [102]. The authors of [104] propose an Ethereum-based approach and especially emphasize the benefits of smart contracts for automatically ensuring access control. The authors of [103] present an approach called ARTICONF. This solution is further elaborated in another publication by some of the authors [86]. ARTICONF, a project funded by the European Horizon 2020 program, aims to develop a new development platform and ecosystem for social media [121]. References [103] and [86] investigate the ARTICONF approach for the use-case of a peer-to-peer, collaborative car-sharing application. The authors of [86] show that their solution enables car-sharing customers to interact in a secure way by simulating a use-case scenario. In addition, customers are able to keep control over their data [86].

Blockchain promises multiple advantages and benefits for ridesharing. Increased security is one that is mentioned most often. Security is a broad term and has many different meanings in the context of ridesharing. In most cases, though, it means security against malicious drivers and riders [95]. However, it can also mean security against data leakages, the violation of privacy, or attacks on one single point of failure. Thus, decentralization is seen by many authors as a key advantage of blockchain $[79,85,87]$. The main reasons are that a centralized network or platform may threaten privacy and lead to dependency on rules fixed by the controlling parties [98]. Furthermore, as already mentioned, a central authority or instance, being a single point of failure, is sometimes seen as a vulnerability or source for possible data leakage [100]. Some authors [94,99,104] mention automatic execution of tasks as an advantage. Automatic execution often refers to the automatization of processes with smart contracts, which are integrated with the blockchain and enable an automated process of matching drivers and riders. Table 6 shows an overview of the advantages and benefits identified by the authors. 
Table 6. Overview of Advantages of Blockchain-Based Ridesharing Solutions.

\begin{tabular}{|c|c|c|c|c|c|c|c|c|c|c|}
\hline Year & Source & $\mathrm{AE}$ & AN & DE & IM & PR & SC & SE & TP & TR \\
\hline 2018 & [94] & $x$ & & $x$ & $x$ & & & $x$ & & $x$ \\
\hline 2019 & [95] & & $x$ & & & & & $x$ & & \\
\hline 2019 & [96] & & & $x$ & & & $X$ & & & \\
\hline 2019 & [97] & & & $X$ & & & & & & $x$ \\
\hline 2019 & [98] & & & $x$ & & $X$ & & $X$ & & \\
\hline 2019 & [99] & $X$ & & $X$ & & & & $X$ & & \\
\hline 2019 & [100] & & & $x$ & $X$ & & & $x$ & $X$ & $X$ \\
\hline 2020 & [101] & & & $X$ & & & & $X$ & $X$ & $X$ \\
\hline 2020 & [102] & & & & & $X$ & & $x$ & & \\
\hline 2020 & [103] & & & $x$ & & $x$ & & $x$ & & $x$ \\
\hline 2020 & [104] & $x$ & & $x$ & & & & $x$ & & $x$ \\
\hline 2021 & [86] & & & $X$ & & $X$ & & $X$ & & $x$ \\
\hline
\end{tabular}

\subsection{Platooning}

Finally, there are use-cases utilizing blockchain in the context of truck platooning. A truck platoon can be defined as a group of self-driving trucks moving together in convoy [122]. Truck platooning presents many advantages, including cost savings due to reduced fuel consumption [122-124], and the resultant reduced emissions [125]. In addition, truck platoons enable more efficient use of the infrastructure by taking up less road space, which reduces the risk of traffic congestion, and increases possible traffic throughput [126-128]. The vehicles participating in a platoon can be divided into two groups. The platoon leader (PL), sometimes also called platoon head (PH), is the first vehicle of a platoon. It is followed by one or more platoon followers or platoon members (PMs) $[106,107]$. The PL fulfills different tasks, for instance, paying attention to the driving situation [129]. The PL is also responsible for the platoon's functioning, involving tasks like sending data to platoon followers or coordinating platoon movement and maneuvers [107]. An illustration of a platoon is depicted in Figure 4.

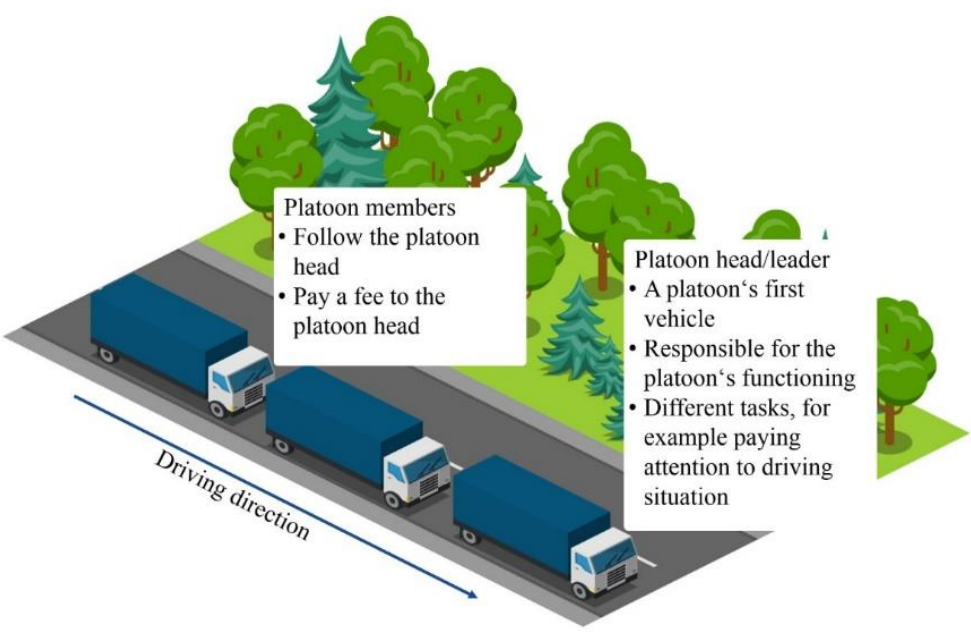

Figure 4. Illustration of a platoon (own representation).

Security problems related to platoons are one major issue that blockchain-based solutions aim to deal with. In traditional platoons, where every member joining the platoon is identified at the beginning and remains until the end of the route, security or leakage of sensitive information is usually not a problem. In dynamic platoons, however, unknown vehicles can join and then leave the platoon later. Different kinds of vehicles can be part of such a platoon, including malicious nodes that want to damage other vehicles' interests or want to launch cyber-attacks. Vehicles may also pretend to be honest, 
yet avoid paying fees when they leave the platoon [108]. The 2018 publication [78] is the first to deal with blockchain's role in the context of platooning. Although originally dealing with securing VANETs using blockchain, [78] focuses on the use-case of platooning. Their main contribution is the development of a proposal to enable vehicles of the same platoon to validate each other's integrity. Although already outlined above, it is also worth mentioning the authors' conclusion that PoW is not a suitable consensus algorithm in a real-time system like a VANET and in platooning.

The authors of [108] focus on platoons consisting of autonomous vehicles. In such an autonomous vehicle platoon (AVP), effectively managing the leaving and joining of vehicles and rewarding the platoon leader are challenging tasks [108]. Therefore, [108] proposes a blockchain-based autonomous vehicle platoon management system (BAVPM). This approach sets up a separate communication space for every single platoon so that all platoon members can only communicate with each other. Communicating with facilities or other vehicles that are not part of the respective platoon is reserved only for the platoon leader. According to the authors, this would decrease the risk of interference between different platoons and increase the overall safety within a platoon. Furthermore, the blockchain's smart contracts enable payments in any case, including when opportunistic vehicles try to escape their duty to pay [108]. In a later work, the same authors also address the scenario of electronic toll collection (ETC) [105]. An ETC is a system that automatically collects tolls from vehicles. Different vehicles need to keep a certain distance from each other to be successfully recognized by the ETC. This leads to the disadvantage that platoons need to split up when passing an ETC and to reform again afterward. One solution for this problem is that the PL pays for the whole platoon. This procedure is difficult in general, as this could lead to problems like PMs escaping after payment without rewarding the PL. To avoid this, [105] propose a blockchain-based approach that enables the PL to pay the toll for the whole platoon without the above-mentioned difficulty. In addition, [106] deals with platoons consisting of autonomous vehicles. Their approach allows autonomous vehicles to automatically form a platoon when a path matching is successful. The authors specifically address the danger of malicious PMs trying to avoid payment to the PL. This difficulty is counteracted with the help of a smart contract that prevents malicious behavior and ensures the PL's payment [106].

The authors of [107] deal with the importance of security in vehicle platoons. They emphasize that every PM can theoretically be controlled by attackers, including the PL. Such an attack might cause damage and lead to risks to the platoon's stability and security. As a countermeasure against these potential attacks, the authors propose a blockchainbased scheme that guarantees that the platoon's most trusted member acts as the PL. With the help of this system, every PM can verify any other PM's reputation, so that malicious actors are excluded from the system. In their approach, DPoS is used as the consensus mechanism. In simulations, the authors of [107] showed that their solution is not only successful for reputation management and updating the PL, but also for reducing wireless communication overhead.

\section{Open Research}

In the previous section we presented and summarized the existing research on blockchain for mobility and transportation purposes. Despite the research that has already been done in this area, there are still many areas and opportunities for future research. In this section's first subsection, we identify future research avenues regarding the five use-cases of blockchain-based mobility. We present an overview of the first subsection in Table 7. below. Furthermore, many of the identified articles deal in an isolated way with only one use-case or application and abstract from relevant details, like the users or the environment in which blockchain-based mobility is embedded. This bracketing of the environment is of course necessary, but also leads to a rather fragmented view that often excludes factors like citizens, cities, or juridic aspects. In the second subsection, we 
therefore focus on research topics that are not directly linked to one specific use-case but are still important to consider.

Table 7. Overview of Open Research Regarding the Use-Cases of Smart Mobility.

\begin{tabular}{|c|c|}
\hline Use Case & Future Research Topics \\
\hline ITS and VANETs & $\begin{array}{l}\text { How can the consensus in a blockchain-based VANET be ensured } \\
\text { and what consensus algorithms are most appropriate? } \\
\text { How does the nodes' mobility affect the consensus-building in a } \\
\text { blockchain-based VANET? } \\
\text { How can individual vehicles be held accountable for malicious } \\
\text { behavior or misuse of network resources? } \\
\text { How can misbehavior be detected, and misbehaving } \\
\text { vehicles reported? } \\
\text { What blockchain system (e.g., Ethereum, Hyperledger Fabric etc.) is } \\
\text { most suitable as the foundation for a blockchain-based VANET? }\end{array}$ \\
\hline Communication & $\begin{array}{l}\text { What consensus mechanism is suitable for vehicular communication? } \\
\text { How can the privacy of the participating users be ensured? } \\
\text { How is vehicular communication best embedded in VANETs? } \\
\text { Where and how is vehicular communication data saved? }\end{array}$ \\
\hline Electric Charging & $\begin{array}{l}\text { How do blockchains change the charging markets, and what are the } \\
\text { market-based implications of this technology? } \\
\text { Can the concept of blockchain-based marketplaces be adapted to the } \\
\text { use-case of vehicle charging? } \\
\text { What are the resulting benefits, advantages, and shortcomings of } \\
\text { adapting blockchain-based marketplaces in the charging context? }\end{array}$ \\
\hline Ridesharing & $\begin{array}{l}\text { How can trust be achieved in blockchain-based ridesharing? } \\
\text { How can coins and tokens be best used to motivate and incentivize } \\
\text { riders and drivers? } \\
\text { Who can benefit from blockchain-based ridesharing, and what are } \\
\text { possible resulting business models? }\end{array}$ \\
\hline Platooning & $\begin{array}{l}\text { Which consensus algorithm is most suitable for the platooning } \\
\text { use-case? } \\
\text { How can blockchain-based platooning be integrated with supply } \\
\text { chain management? } \\
\text { How can blockchain-based platoons be integrated with ETC? } \\
\text { How robust and secure are blockchain-based platoons relative to } \\
\text { malicious vehicles, and how can the security be increased? }\end{array}$ \\
\hline
\end{tabular}

\subsection{Open Research Regarding the Use-Cases}

ITS and VANETs: ITS and VANETs are the underlying architecture for many future usecases in smart mobility. The research already contains many proposals on how blockchain can be used in the context of an ITS or VANET, and what the resulting benefits might be. Despite all the work done, however, several open questions still remain. First, the question of how misbehavior can be detected reliably is something that needs closer investigation [87]. Although initial ideas exist, these must be rigorously tested in a realworld setting as a next step. Furthermore, the technical foundation for the blockchain-based VANETs is an issue that needs to be discussed. Right now, Ethereum and Hyperledger Fabric are discussed most often in relation to smart mobility. This also presents the question of the consensus algorithm that is used. Many authors found PoW to be an suitable consensus algorithm in a VANET $[78,116]$. The fact that the different vehicles in a VANET are mobile and moving [116] is also an interesting facet.

Communication: Communication between (autonomous) vehicles will be a fundamental part of future mobility. As with almost all applications, it remains unclear which consensus algorithm is most suitable. Based on experimental results, Wagner and McMillin [78] showed that PoW is not an appropriate way to reach consensus in real-time systems. Furthermore, the same authors emphasize the importance of security and privacy within 
blockchain-based vehicular communication systems. This is also highlighted by other authors who state that "how to jointly assure the privacy preservation and efficient trust management is still an interesting but challenging problem in vehicular networks" [88] (p. 1503).

Another important question that needs to be addressed is what happens with the data that is exchanged during vehicular communication. Storing the data of vehicular communication might lead to several benefits. For example, due to blockchain's immutability and tamper-proof character, the data from vehicles or traffic events might help to understand the cause of accidents. The aggregated vehicular data might also help cities to better understand the flow of traffic and the emergence of congestion, or to get information about road conditions.

Electric Charging: The impact of blockchain on market functions, particularly in the use-case of electric charging, is worth investigating. Although there is no direct link to this idea in their articles, the concepts of both [93] and [92] can be interpreted as varieties of blockchain-based marketplaces (BBM). The idea of blockchain-based marketplaces was initially proposed in [130]. These decentralized marketplaces are supposed to be a countermeasure to marketplaces that are controlled by an organization or company. The controlling intermediary of the marketplace is replaced by the network of nodes. This blockchain network is responsible for the infrastructure, matching buying and selling parties, and ensures that transactions are fulfilled [130]. Blockchain-based marketplaces are supposed to have several advantages and benefits. For a distributed online marketplace based on Ethereum, [131] showed that costs are less than that of Amazon or eBay for a large number of users. Blockchain-based marketplaces have already been proposed for different use-cases, like IoT data [132], software testing [133], or trading of agricultural products between farmers and other stakeholders [134]. It might make sense to investigate whether blockchain-based electric charging can also be realized with a marketplace structure and what the resulting benefits and disadvantages are.

Ridesharing: Trust is one crucial factor for the acceptance of blockchain-based ridesharing. Two facets of trust that are of particular importance in the context of the sharing economy are the trust in peers and the trust in the platform. First, trust in peers means the trust between consumers and providers [135]. In the mobility context, this therefore means the trust between the riders and the drivers. On the other hand, trust in the platform is related to the trust in the sharing economy platform [135]. The role and influence of blockchains on trust have already been extensively discussed in research $[122,136,137]$. However, to the best of our knowledge, trust has not currently been investigated in the context of blockchain-based ridesharing. Therefore, we see this as one of the most important research gaps, since trust in the platform and other users are key factors in the sharing economy [137].

Platooning: Furthermore, future research should address the question of which consensus algorithm is most suitable for a blockchain in the platooning context. The authors of [78] conclude that PoW is not suitable for real-time scenarios and applications like VANETs and platooning. There are many possible alternatives. Apart from better known solutions like PoS or PoA, several other ideas for possible consensus algorithms exist. Examples are the already presented PoAI, PoD, or, as also suggested by [78], Proof of Burn (PoB). It might also be possible to develop new consensus algorithms that are tailored to the platooning purpose. Furthermore, one possible future research direction is the question of how ETC can best be realized with blockchain-based platoons. As outlined above, a first approach to tackle this issue is proposed in [105]. However, to the best of our knowledge, there is no research about the question of how ETC itself could be realized with a blockchain. In general, ETC is a use-case that might be a suitable technology for blockchain. A blockchainbased ETC would therefore be another use-case not investigated yet. A blockchain-based ETC would enable automatic payments from the platoon's blockchain to the ETC system's blockchain. This could probably avoid the necessity of a platoon stopping and realizing a toll payment while passing an ETC station. 


\subsection{Open Research regarding General Topics}

Blockchain is a technology that has multiple effects in many different areas. Apart from technical topics, blockchain has implications for society, jurisdiction, businesses and the general economy [138]. In addition to use-case-specific research avenues, we therefore also consider it necessary to address the question of future research from a higherlevel perspective. In the following subsection, we view this from technical, juridical, and economic perspectives. Furthermore, we outline future research on the topic of smart cities, including the effects on citizens themselves. An overview of future research topics regarding general topics is given in Table 8.

Table 8. Overview of Open Research Regarding General Topics.

\begin{tabular}{|c|c|}
\hline Use Case & Future Research Topics \\
\hline Technology & $\begin{array}{l}\text { How can other technologies be integrated with blockchain } \\
\text { technologies that are used for smart mobility purposes? } \\
\text { How can blockchain be used to support other technologies in the } \\
\text { context of mobility, for example, AI? } \\
\text { What blockchain systems (e.g., Ethereum, Hyperledger Fabric } \\
\text { etc.) are most suitable for use in the context of smart mobility? } \\
\text { How can smart contracts be created efficiently and securely for } \\
\text { smart mobility purposes? } \\
\text { How can AI help to make smart contracts in the context of smart } \\
\text { mobility more efficient and elaborate? } \\
\text { What are security and privacy risks that need to be addressed? }\end{array}$ \\
\hline Cities and Government & $\begin{array}{l}\text { Should blockchain systems for smart mobility be embedded in, or } \\
\text { connected to, other blockchain solutions in smart cities? What } \\
\text { would be resulting advantages and challenges of such } \\
\text { an integration? } \\
\text { How can blockchain be used for public transport? } \\
\text { What are the costs for cities when using blockchain in } \\
\text { smart mobility? } \\
\text { How can blockchain systems of different cities be integrated for } \\
\text { city-spanning mobility and transportation? } \\
\text { How can citizens be best integrated in the development, } \\
\text { prototyping, and usage of blockchain-based mobility solutions? } \\
\text { How can blockchain-based solutions help smart cities to become } \\
\text { smart tourism destinations? }\end{array}$ \\
\hline Citizens and tourists & $\begin{array}{l}\text { How can citizens' data safety in blockchain-based smart mobility } \\
\text { solutions be ensured? } \\
\text { What features do blockchain-based solutions need to lead to good } \\
\text { usability for and acceptability by citizens? } \\
\text { How can citizens be integrated in the development of new } \\
\text { blockchain solutions for smart mobility? } \\
\text { How can long-term satisfaction be guaranteed? } \\
\text { citizen's motivation or behavior? } \\
\text { How can coins or tokens on a blockchain be used to incentivize } \\
\text { terms of their user behavior? } \\
\text { How can tourists in a city and their mobility needs be covered } \\
\text { and addressed by blockchain-based solutions? }\end{array}$ \\
\hline
\end{tabular}


Table 8. Cont.

\begin{tabular}{c} 
Future Research Topics \\
\hline Whe Case $\begin{array}{c}\text { What implications does blockchain have for jurisdiction and law } \\
\text { in the traffic sector? }\end{array}$ \\
What potential can blockchain unleash as support for road \\
traffic compliance? \\
How can blockchain help prevent road traffic crime? \\
What can blockchain contribute to automatic speed regulation? \\
How can blockchain help to comply with or verify legal \\
requirements in ridesharing? \\
What impacts do regional specifics in law have for \\
blockchain-based smart mobility? \\
What are the potentials for decentralized \\
autonomous organizations? \\
How can smart mobility applications be realized in the form of \\
blockchain-based marketplaces? \\
What revenue models exist in blockchain-based smart mobility? \\
How can blockchains for supply chain management be integrated \\
with mobility blockchains? \\
How can tourism revenues be generated or increased through \\
blockchain-based smart mobility solutions?
\end{tabular}

Technology: One interesting technological topic that is worth investigating in the future is the combination of blockchain with other technologies. As outlined above, the convergence of blockchain with other developments, such as AI or IoT, is a topic discussed within different fields. The convergence of blockchain and AI, especially, has seen an increase in interest over the past years. Blockchain can be used to support AI, referred to as blockchain for AI, and vice versa, named AI for blockchain. [84] already proposed the use of AI to enhance smart contracts and the blockchain's mining process. All these use-cases fall within the field of AI for blockchain, as AI helps overcome blockchain-related problems or inefficiencies. However, use-cases of blockchain for AI might also make sense in the context of smart mobility. AI is the foundation for many future mobility applications, for example autonomous cars [139]. Therefore, the blockchain might be indirectly used for mobility by enhancing AI systems used in a mobility context. To the best of our knowledge, no research in this area currently exists, although several opportunities might be worth investigating.

Furthermore, as already mentioned above, blockchain cannot be viewed as one single, unified technology. Instead, blockchains differ in various aspects, including identity management, charging and rewarding systems, and the ways in which security and consensus is ensured [30]. Blockchains are therefore characterized by a number of different components and properties. For that reason, there are a lot of possible, conceivable blockchain system configurations. Which configuration is most suitable for use-cases in smart mobility is therefore an important question that needs to be addressed and evaluated. Most likely, different blockchain systems are also most suitable for different smart mobility applications.

Security and privacy issues with smart mobility are the most common problems that blockchain solutions seek to address. Although blockchain is often considered to be secure and privacy-preserving, there have been numerous security breaches of blockchain systems in the past [140]. Therefore, security and privacy are important aspects that need to be considered when designing blockchain-based mobility solutions. Often, insecure smart contracts present one of the main causes of security problems or accidents [71]. Future research must therefore urgently take these issues into account and treat safety and privacy of blockchains in the context of mobility seriously. Unpleasant consequences that could otherwise turn into threats would be, for example, fraud in blockchain-based platoons, data loss, or the theft of assets or coins that are deposited on the blockchain. Such accidents could significantly reduce the adoption level of blockchains for transportation applications. 
Consequences would be an unwillingness by citizens or tourists to use them, as well as legal or financial consequences for cities.

Cities and Government: One area in which cities might benefit from the blockchain is public transportation using trains, subways, or buses. Usually, this requires the purchase of tickets by the passengers. This process could also be transferred to the blockchain and thus become an integrated part of an overarching blockchain system. This idea is already partially addressed in [97]. However, to the best of our knowledge, there is no proposal for a blockchain-based ticket payment system in the context of public transportation yet. Blockchain for public transportation would therefore be a new use-case worth investigating in future research.

For cities, it might make sense not to think in an isolated way, but to consider integrated blockchain systems. Many of the identified solutions we outline in this article focus on one single use-case of smart mobility. If different blockchain solutions exist for different use-cases, however, this might impair user-friendliness. In a smart city context, it can be expected that it might be difficult to convince the citizens to become members of different blockchain networks related to mobility. For instance, if one user earned coins on one blockchain for offering ridesharing, these coins could not be spent immediately to charge the vehicle; it would be necessary to transfer the coins or to exchange them to real money beforehand. These difficulties might hinder the acceptability of using the different blockchains due to a lack of integrability. With one single, overlapping blockchain it would be possible to spend the same coins for different activities or services. Citizens would then be able to get coins for different activities, for example, sending information about the current traffic situation or transporting other citizens through ridesharing. After that, the same coins stored on the same blockchain could be used, for example, to charge the owner's electric vehicle, to use ridesharing as a customer, or to buy public transportation tickets. We therefore argue that a solution trying to merge the different applications of the blockchain in the context of smart mobility would lead to many benefits. Having separate blockchains or systems for all these different applications seems counterintuitive and would result in several disadvantages. Given its potential, we think future research needs to investigate what such an overarching blockchain or smart mobility system should look like. It is noteworthy that blockchain's potential is also investigated for other aspects of smart cities, such as smart healthcare or the smart grid [22]. Therefore, it might make sense to integrate smart mobility solutions and implement an overarching solution for different smart city use-cases. This also involves the aspect of smart tourism and a cities ambition to become a smart tourism destination [141]. This aspect will be covered below.

Citizens and tourists: Citizens, being the core of cities, have often been considered in smart city research, as has their use of technology. The blockchain and its potential for citizens has also been addressed by research. Impressive potential is seen in the storage and exchange of personal data (e.g., [142]) or the improvement of citizens' activities [143]. When the blockchain is applied to smart mobility, smart citizens will be the users of these systems. Therefore, citizens are always an important factor when planning, creating, and evaluating blockchain applications for smart mobility. One important issue to consider is the citizens' personal data that increases exponentially. When using blockchain for mobility purposes, it is important to investigate which data are generated and how these must be protected. Furthermore, citizens must accept new technologies to use them. Therefore, research is necessary about the factors that influence citizens' levels of acceptance. The usability of the system is also an important item. It requires a careful investigation of how the blockchain systems must be designed and which functionalities are most important for the citizens. Future research about citizens can only partially be viewed as isolated, as citizens are an embedded part of cities and of a legal system, and they use and interact with technology. Therefore, legal, economic, and societal aspects have to be included in the future discussion of citizens' roles in and interaction with blockchain-based smart mobility.

One further aspect that is not yet covered by existing literature is that of tourism. Smart cities not only use ICT for enhancing the experience of their own citizens, but 
also for tourists visiting a city $[144,145]$. As a result of these initiatives, smart cities can develop into so-called smart tourist destinations [141]. As shown in previous studies, smart systems increase the tourists' satisfaction with, and attraction to, a destination [144,146,147]. Previous literature also considers the role of smart mobility as one important factor in smart tourism [148]. Mobility is an important factor for tourists and essential for their comfort, especially in large cities [149]. Smart cities with smart tourism ambitions therefore should investigate how blockchain-based smart mobility applications can benefit the cities' tourism. Right now, current research only investigates blockchain for specific use-cases. The literature does not yet cover the implications for tourists as one specific type of user. For example, blockchain-based ridesharing might also be beneficial for tourists visiting a city without their own vehicle. Public transport, a sub-sector which has also so far been ignored by blockchain research, is closely related to tourism. Here, it would be valuable to find out how tourists can best be involved in public transport solutions.

Law: The blockchain as a new technology has many legal implications. Smart contracts are a blockchain-related topic of direct relevance. If personal data is involved or processed, data protection laws also need to be considered in the context of smart contracts [150]. In addition, laws also require special regional adjustments to legislation. Two examples are the California Consumer Privacy Act (CCPA) or the EU General Data Protection Regulation (GDPR), a data protection rule that is effective in the European Union and has many implications for companies dealing with data (see, e.g., [151] or [152]). In the context of blockchain-based smart mobility, it is also possible that the underlying blockchain system suffers from security flaws or technical issues. It is still unclear who is responsible and what will happen in such a case if anyone is harmed.

Economy: Although blockchain is a new and trending technology, its value-creation role is generally still not widely explored [153]. Blockchain and cryptocurrencies could disrupt many industries and serve as the foundation for a new generation of financial services [154]. Since blockchain can be applied in various fields, it presents opportunities for value creation and new business models for technology entrepreneurs and especially start-up companies [153]. Blockchain-based smart mobility solutions could also hold potential for new value creation or business models for cities. As outlined above, a city's tourism may be able to benefit from the use of blockchain for smart mobility. It could also be complicated and tedious to keep track of all the different blockchains and their account balances. Combined with intelligent and autonomous vehicles, such an approach could make even more use-cases possible. For instance, self-driving trucks would be able to automatically drive in platoons, deliver goods or products, communicate with each other, and charge themselves without any human intervention. Through this possibility, a basis for a decentralized autonomous organization (DAO) could be created. In relation to this article, the term DAO appears for the first time in December 2013 in the white paper on the Ethereum platform [155]. Here, the DAO is defined as a virtual unit or company with a certain number of members or shareholders who have different rights. These shareholders can decide, for example, whether the source code is to be changed or what the DAO spends its assets on [155]. In his description of DAOs, the author of [156] includes the role of smart contracts and describes a DAO as an organization governed by rules encoded by smart contracts. The recording of financial transactions and the programmed rules of a DAO are managed in a blockchain [156]. In the future, the development of an intelligent DAO of autonomous trucks that fulfill logistic processes themselves might be possible. Intelligent DAOs would be a new organization with completely new implications for society, the economy and involved stakeholders. However, those ideas are highly speculative and far removed from being a practical realization right now.

Figure 5 is a visualization of the interdependencies of the use-cases with each other as well as with the environment. First, we can conclude that the use-case of blockchain-based smart mobility, shown in the inner cycle of Figure 5, cannot be viewed in isolation. These are instead embedded in an environment. This environment consists of, among other things, the city in which the mobility takes place, the citizens of that city who use the 
smart mobility system, and the applicable judicial framework. We therefore emphasize the importance and necessity for future research to adopt a holistic view by also considering the environment of smart mobilities. Furthermore, we assume that the five applications of blockchain-based smart mobility are logically connected to each other. As outlined above, we see promising future research opportunities within one specific use-case of blockchain-based mobility and in investigating the potential and advantages of blockchain systems that cover multiple facets of mobility or transportation.

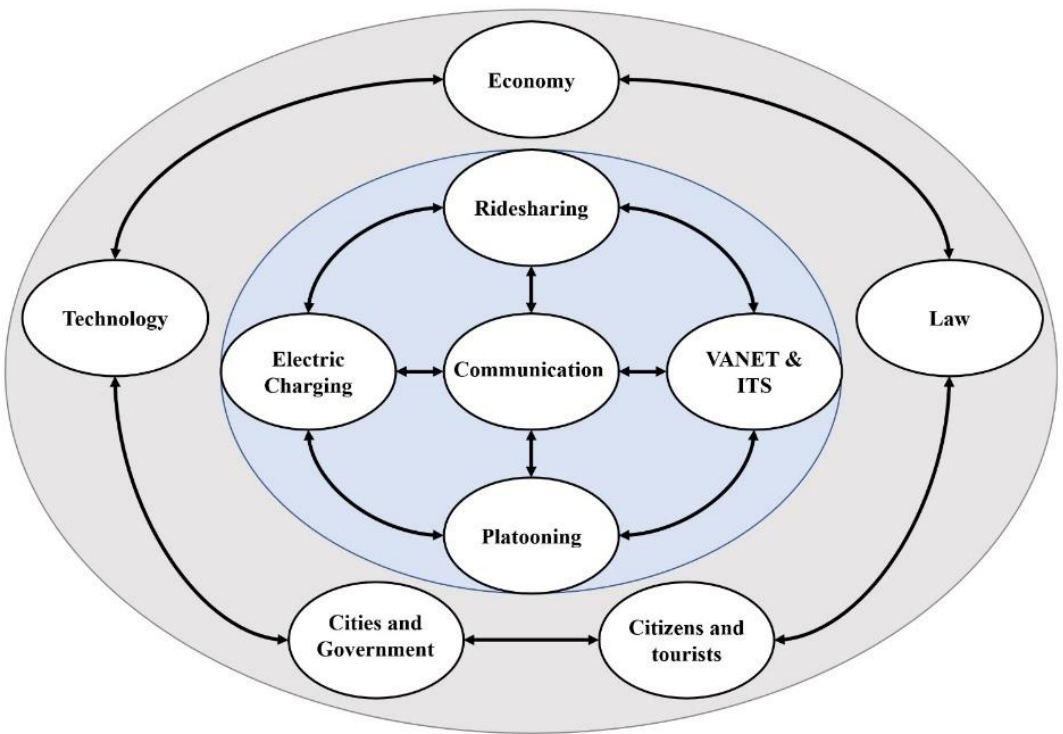

Figure 5. Holistic view of the research areas (own representation).

\section{Key Contributions and Discussion}

We conducted a systematic review of the literature on the use of blockchain for smart mobility and transportation. A first main contribution of our work is an initial classification of existing research. As our review of the current literature shows, there are five different categories of applications of the ways in which the blockchain can help or be utilized in the context of smart mobility: First, blockchain can be used to enhance or improve ITS and VANETs. In addition, blockchain can be used in the context of vehicular communication. Furthermore, electric charging is an important infrastructural factor that future mobility blockchain can be used for. Next to VANETs and ITS, blockchain for ridesharing is the use-case on which most research has been done so far. Here, the varied potential is seen as increased security and privacy for users. Finally, blockchain can serve as an infrastructural and technological foundation for truck platoons. In our review results section, we gave a detailed overview of existing approaches, their intended advantages and benefits, and their potential shortcomings. As such, our results aim to provide interested scientists with an initial understanding of the emerging field of blockchain in a mobility context. Furthermore, the individual subsections of the results also allow a detailed examination of individual application areas. Therefore, our results can present the reader with the current state of research and existing publications for each application area.

Regardless of the specific mobility use-case, security and privacy are the problems that blockchain-based solutions most often seek to address. In the context of VANETs, where different vehicles communicate with each other and with the infrastructure, security is an especially important aspect. Due to the wireless nature of this communication, VANETs are vulnerable to attackers that change or alter information. Here, for example, blockchain can help users obtain the trust values of other participants and received messages [88], or enable secure key management between different vehicles [76]. In the context of ridesharing, blockchain is supposed to solve different security-related problems. The authors of [95] address the issue of misbehaving and malicious users that could send multiple messages 
without committing, for example. They propose a solution that forces users to send a deposit on a blockchain. The proposed time-locked deposit protocol suggested by the authors of [95] can therefore avoid malicious behavior from both riders and drivers.

Furthermore, vehicles participating in ridesharing platforms must share private information which is stored in a centralized and controlling instance. This centralization presents the issue of possible data leakages that threaten individual privacy [100]. Due to its decentralized nature, blockchain may be a possible answer to these security issues, since it avoids a single point of failure. Malicious vehicles that can compromise the security of a platoon posit a major threat to platoon configurations. This can happen, for example, through targeted cyberattacks or denial and misappropriation of payments. Here, the blockchain can help to increase the security of platoons in various ways, for instance, by allowing vehicles to validate each other's integrity or by using smart contracts that force malicious platoon members to pay a fee. Even though blockchain is supposed to promise more security for mobility, it can also contribute to new security problems. As mentioned in the previous section, faulty smart contracts, especially, can lead to serious security issues. Thus, for blockchains to be effective in increasing security and not lead to new problems, the issue of security must also play an important role in the development of blockchain solutions for smart mobility.

In addition, a literature review can help to advance a research field by integrating the findings from a broad range of existing studies $[157,158]$. As such, we believe that a systematic literature review can, and should, identify key research gaps and serve as a platform and foundation for further research [23]. In the previous section, we therefore developed a future research agenda as our second contribution. First, we identified research gaps and future research questions for the use-cases and application areas we identified in the review results section. However, future research opportunities do not only exist for the individual sub-areas of smart mobility that have already been identified by previous research. Due to the rapid development of technology, the comprehensiveness of the use-cases contained in our literature review is only temporary. It can be assumed that new applications will appear that are not yet included in our categorization. For example, other subsectors of mobility and transportation are conceivable in which a blockchain might make sense, for example, ETC and public transportation. Additionally, an integrated blockchain that combines different areas of mobility or smart cities might be an idea for further investigation.

Apart from this, future research should consider the fact that blockchain-based mobility is also connected to, and embedded within, other topics. First, technical developments and aspects influence blockchain solutions for smart mobility. Although extensive research exists from a technical point of view, blockchain is a steadily changing technology. Therefore, technical advances in blockchain technology will continue to present new influences, potentials, and implications for smart mobility. Furthermore, the integration of blockchain with other technologies, for example AI, are future developments that will also impact blockchain-based mobility. Apart from technical questions, blockchain-based mobility can be viewed through an economical or a juridical lens. In addition, cities and the citizens or tourists as the users themselves can be considered to form the focus of future research projects.

Many results outlined in this article are only theoretical in nature, due to the lack of prototypes or any practical application and most of the approaches identified in the existing literature have not been tested extensively in a real-world scenario. Future research can therefore avail itself of many opportunities to systematically create and evaluate technical artifacts in real use-cases. Design Science Research (DSR) is one method that might be suitable for generating further insights. DSR aims to create socio-technical artifacts and design knowledge to produce new solutions for real-world problems [159-161]. Furthermore, one goal of DSR can be to create generalizable knowledge in the form of design requirements and design principles. Such future research contributions would be particularly valuable, because previous approaches are still isolated from each other. Generalizable principles 
that a blockchain-based solution should have for specific mobility application areas could not be identified so far.

This study has limitations that need to be considered in future research. First, the literature collection was limited to specific databases. Although we consider our selected databases as the most relevant and significant ones, the selection of particular databases can cause specific contributions or publications to be overlooked and therefore not be part of this research. Furthermore, research on blockchain and its application areas develops very fast. The results in this paper are therefore only an illustration of current research. Future studies will lead to new insights and use cases that have not been considered in this thesis. Moreover, this paper contributes only to the conceptual level by structuring the field of blockchain for smart mobility, which we consider to be the main limitation of this research. Future research should therefore focus on evaluating blockchain-based mobility solutions applied in a real-world scenario.

\section{Conclusions}

Due to the increasing urban population, today's cities are confronted with several challenges. Cities also have a significant impact on the environment and climate change. Smart cities try to find new solutions for today's challenges caused by urbanization and environmental change. Mobility and transportation form one crucial aspect of today's cities. Efficient and sustainable mobility is a precondition to avoid problems like traffic congestion, to ensure a high quality of life for a city's residents and tourists, and to reduce carbon emissions and environmental pollution. The use of blockchain for smart mobility use-cases has already been addressed by research. However, despite the initial work in this area, the research is still fragmented and sometimes barely sufficiently integrated. With this review, we aim at closing this gap and providing an overview of the current state of the art in blockchain for smart mobility. We did so by categorizing the applications of blockchain for smart mobility into five different use-cases. As a result of our review results, and the link to other research, we developed a future research agenda. This can serve as a foundation for future research endeavors within this promising and emerging field.

Given the fast development of blockchain and other technologies, this paper's results only represent the current state of the research. We assumed that there will be a variety of future developments in the field of blockchain. These will also have an impact on the application area of blockchain in the context of smart mobility we outlined in this article. However, we believe that we succeeded in providing interested researchers with a current overview of this emerging research field, its applications, and future research opportunities.

Author Contributions: Conceptualization, E.K. and M.J.; methodology, E.K.; formal analysis, E.K.; investigation, E.K. and M.J.; writing—original draft preparation, E.K. and M.J.; writing-review and editing, F.A. and E.K.; visualization, E.K.; supervision, E.K.; project administration, E.K. and M.J. All authors have read and agreed to the published version of the manuscript.

Funding: This research received no external funding.

Institutional Review Board Statement: Not applicable.

Informed Consent Statement: Not applicable.

Acknowledgments: We acknowledge support by the Open Access Publication Fund of the University of Duisburg-Essen.

Conflicts of Interest: The authors declare no conflict of interest.

\section{References}

1. Seto, K.C.; Dhakal, S.; Bigio, A.; Blanco, H.; Delgado, G.; Dewar, D.; Huang, L.; Inaba, A.; Kansal, A.; Lwasa, S.; et al. Human settlements, infrastructure and spatial planning. In Climate Change 2014: Mitigation of Climate Change: Contribution of Working Group III to the Fifth Assessment Report of the IPCC; IPCC-Intergovernmental Panel on Climate Change, Ed.; Cambridge University Press: Cambridge, UK; New York, NY, USA, 2014; pp. 923-1000. 
2. United Nations. Urban Environment Related Mitigation Benefits and Cobenefits of Policies, Practices and Actions for Enhancing Mitigation Ambition and Options for Supporting Their Implementation. Available online: https://unfccc.int/sites/default/files/ resource/docs/2017/tp/02.pdf (accessed on 1 December 2020).

3. United Nations. $68 \%$ of the World Population Projected to Live in Urban Areas by 2050, Says UN. Available online: https: //www.un.org/development/desa/en/news/population/2018-revision-of-world-urbanization-prospects.html (accessed on 19 January 2020).

4. Suzuki, L.R. Smart Cities IoT: Enablers and Technology Road Map. In Smart City Networks; Rassia, S.T., Pardalos, P.M., Eds.; Springer International Publishing: Cham, Switzerland, 2017; pp. 167-190, ISBN 978-3-319-61312-3.

5. Kummitha, R.K.R. Smart cities and entrepreneurship: An agenda for future research. Technol. Forecast. Soc. Chang. 2019, 149, 119763. [CrossRef]

6. Shahrokni, H.; Årman, L.; Lazarevic, D.; Nilsson, A.; Brandt, N. Implementing Smart Urban Metabolism in the Stockholm Royal Seaport: Smart City SRS. J. Ind. Ecol. 2015, 19, 917-929. [CrossRef]

7. Sun, J.; Yan, J.; Zhang, K.Z.K. Blockchain-based sharing services: What blockchain technology can contribute to smart cities. Financ. Innov. 2016, 2, 93. [CrossRef]

8. Papa, E.; Lauwers, D. Smart Mobility: Opportunity or Threat to Innovate Places and Cities? In 20th International Conference on Urban Planning and Regional Development in the Information Society; Schrenk, M., Popovič, V.V., Zeile, P., Elisei, P., Beyer, C., Eds.; CORP: Vienna, Austria, 2015; ISBN 9783950311099.

9. Batty, M.; Axhausen, K.W.; Giannotti, F.; Pozdnoukhov, A.; Bazzani, A.; Wachowicz, M.; Ouzounis, G.; Portugali, Y. Smart cities of the future. Eur. Phys. J. Spec. Top. 2012, 214, 481-518. [CrossRef]

10. Orecchini, F.; Santiangeli, A.; Zuccari, F.; Pieroni, A.; Suppa, T. Blockchain technology in smart city: A new opportunity for smart environment and smart mobility. In International Conference on Intelligent Computing \& Optimization; Springer: Cham, Switzerland, 2018; pp. 346-354.

11. Desdemoustier, J.; Crutzen, N.; Giffinger, R. Municipalities' understanding of the Smart City concept: An exploratory analysis in Belgium. Technol. Forecast. Soc. Chang. 2019, 142, 129-141. [CrossRef]

12. Giffinger, R.; Fertner, C.; Kramar, H.; Meijers, E. City-Ranking of European Medium-Sized Cities. Cent. Reg. Sci. Vienna UT 2007, 1-12. Available online: http://www.smart-cities.eu/download/city_ranking_final.pdf (accessed on 20 November 2021).

13. Morris, E.A. Should we all just stay home? Travel, out-of-home activities, and life satisfaction. Transp. Res. Part A Policy Pract. 2015, 78, 519-536. [CrossRef]

14. Hays, T.; Olds, P.; Spence, J. Happiness and Traffic: An Analysis of Long Term Effects. 2016. Available online: https://smartech gatech.edu/handle/1853/56032 (accessed on 26 November 2021).

15. Choi, J.; Coughlin, J.F.; D'Ambrosio, L. Travel time and subjective well-being. Transp. Res. Rec. 2013, 2357, 100-108. [CrossRef]

16. Neirotti, P.; de Marco, A.; Cagliano, A.C.; Mangano, G.; Scorrano, F. Current trends in Smart City initiatives: Some stylised facts. Cities 2014, 38, 25-36. [CrossRef]

17. Vecchio, P.D.; Secundo, G.; Maruccia, Y.; Passiante, G. A system dynamic approach for the smart mobility of people: Implications in the age of big data. Technol. Forecast. Soc. Chang. 2019, 149, 119771. [CrossRef]

18. Laumbach, R.J.; Kipen, H.M. Respiratory health effects of air pollution: Update on biomass smoke and traffic pollution. J. Allergy Clin. Immunol. 2012, 129, 3-11. [CrossRef]

19. Nakamoto, S. Bitcoin: A Peer-to-Peer Electronic Cash System. Available online: https://bitcoin.org/bitcoin.pdf (accessed on 24 October 2019).

20. Raval, S. Decentralized Applications: Harnessing Bitcoin's Blockchain Technology, 1st ed.; O'Reilly Media: Sebastopol, CA, USA, 2016; ISBN 1491924543.

21. Lopez, D.; Farooq, B. A blockchain framework for smart mobility. In Proceedings of the 2018 IEEE International Smart Cities Conference (ISC2), Kansas City, MO, USA, 16-19 September 2018.

22. Xie, J.; Tang, H.; Huang, T.; Yu, F.R.; Xie, R.; Liu, J.; Liu, Y. A Survey of Blockchain Technology Applied to Smart Cities: Research Issues and Challenges. IEEE Commun. Surv. Tutor. 2019, 21, 2794-2830. [CrossRef]

23. Paul, J.; Criado, A.R. The art of writing literature review: What do we know and what do we need to know? Int. Bus. Rev. 2020, 29, 101717. [CrossRef]

24. Diffie, W.; Hellman, M. New directions in cryptography. IEEE Trans. Inform. Theory 1976, 22, 644-654. [CrossRef]

25. Merkle, R.C. Secrecy, Authentication, and Public key Systems. Doctoral Dissertation, Stanford University, Standford, CA, USA, 1979.

26. Rabin, M.O. Digitalized Signatures. In Foundations of Secure Computation; DeMillo, R.A., Ed.; Academic Press: New York, NY, USA, 1978; pp. 155-166, ISBN 0122103505.

27. Sedlmeir, J.; Buhl, H.U.; Fridgen, G.; Keller, R. The Energy Consumption of Blockchain Technology: Beyond Myth. Bus Inf. Syst. Eng. 2020, 62, 599-608. [CrossRef]

28. Zheng, Z.; Xie, S.; Dai, H.-N.; Chen, W.; Chen, X.; Weng, J.; Imran, M. An overview on smart contracts: Challenges, advances and platforms. Future Gener. Comput. Syst. 2020, 105, 475-491. [CrossRef]

29. Treiblmaier, H. The impact of the blockchain on the supply chain: A theory-based research framework and a call for action. SCM 2018, 23, 545-559. [CrossRef] 
30. Tasca, P.; Tessone, C.J. A Taxonomy of Blockchain Technologies: Principles of Identification and Classification. Ledger 2019, 4, 1-39. [CrossRef]

31. Peters, G.W.; Panayi, E. Understanding Modern Banking Ledgers through Blockchain Technologies: Future of Transaction Processing and Smart Contracts on the Internet of Money. Available online: http://arxiv.org/pdf/1511.05740v1 (accessed on 13 February 2021).

32. Ziolkowski, R.; Miscione, G.; Schwabe, G. Decision Problems in Blockchain Governance: Old Wine in New Bottles or Walking in Someone Else's Shoes? J. Manag. Inf. Syst. 2020, 37, 316-348. [CrossRef]

33. Rejeb, A.; Treiblmaier, H.; Rejeb, K.; Zailani, S. Blockchain research in healthcare: A bibliometric review and current research trends. J. Data Inf. Manag. 2021, 3, 109-124. [CrossRef]

34. Jensen, T.; Hedman, J.; Henningsson, S. How TradeLens Delivers Business Value with Blockchain Technology. MISQE 2019, 18, 221-243. [CrossRef]

35. Mattke, J.; Maier, C.; Hund, A.; Weitzel, T. How an Enterprise Blockchain Application in the U.S. Pharmaceuticals Supply Chain is Saving Lives. MISQE 2019, 18, 245-261. [CrossRef]

36. Susskind, J. Decrypting Democracy: Incentivizing Blockchain Voting Technology for an Improved Election System. San Diego Law Rev. 2017, 54, 785-828.

37. Treiblmaier, H.; Sillaber, C. The impact of blockchain on e-commerce: A framework for salient research topics. Electron. Commer. Res. Appl. 2021, 48, 101054. [CrossRef]

38. Uddin, M.; Stranieri, A.; Gondal, I.; Balasubramanian, V. A Survey on the Adoption of Blockchain in IoT: Challenges and Solutions. Blockchain Res. Appl. 2021, 100006. [CrossRef]

39. Pandl, K.D.; Thiebes, S.; Schmidt-Kraepelin, M.; Sunyaev, A. On the Convergence of Artificial Intelligence and Distributed Ledger Technology: A Scoping Review and Future Research Agenda. IEEE Access 2020, 8, 57075-57095. [CrossRef]

40. Karafiloski, E.; Mishev, A. Blockchain solutions for big data challenges: A literature review. In Proceedings of the IEEE EUROCON 2017-17th International Conference on Smart Technologies, Ohrid, Macedonia, 6-8 July 2017; IEEE: Piscataway, NJ, USA, 2017; pp. 763-768.

41. Szabo, N. Smart contracts: Building blocks for digital markets. EXTROPY J. Transhumanist Thought 1996, 16. Available online: https://www.fon.hum.uva.nl/rob/Courses/InformationInSpeech/CDROM/Literature/LOTwinterschool2006/szabo. best.vwh.net/smart_contracts_2.html (accessed on 20 November 2021).

42. Iansiti, M.; Lakhani, K.R. The truth about blockchain. Harv. Bus. Rev. 2017, 95, 118-127.

43. Bogner, A.; Chanson, M.; Meeuw, A. A Decentralised Sharing App running a Smart Contract on the Ethereum Blockchain. In Proceedings of the 6th International Conference on the Internet of Things, Stuttgart, Germany, 7-9 November 2016; pp. 177-178.

44. Zhang, Y.; Wen, J. An IoT electric business model based on the protocol of bitcoin. In Proceedings of the 201518 th International Conference on Intelligence in Next Generation Networks, Paris, France, 17-19 February 2015; IEEE: Piscataway, NJ, USA, 2015; pp. 184-191, ISBN 978-1-4799-1866-9.

45. McCorry, P.; Shahandashti, S.F.; Hao, F. A Smart Contract for Boardroom Voting with Maximum Voter Privacy. In International Conference on Financial Cryptography and Data Security; Springer: Cham, Switzerland, 2017; pp. 357-375, ISBN 978-3-319-70971-0.

46. Yasin, A.; Liu, L. An Online Identity and Smart Contract Management System. In Proceedings of the 2016 IEEE 40 th Annual Computer Software and Applications Conference, Atlanta, Georgia, 10-14 June 2016; IEEE: Piscataway, NJ, USA, 2016; pp. 192-198, ISBN 978-1-4673-8845-0.

47. Bryans, D. Bitcoin and Money Laundering: Mining for an Effective Solution. Indiana Law J. 2014, 89, 441.

48. Shcherbak, S. How should Bitcoin be regulated? Eur. J. Leg. Stud. 2014, 7, 45-91.

49. Van Wegberg, R.; Oerlemans, J.-J.; van Deventer, O. Bitcoin money laundering: Mixed results? An explorative study on money laundering of cybercrime proceeds using bitcoin. J. Financ. Crime 2018, 89, 419-435. [CrossRef]

50. Zheng, Z.; Xie, S.; Dai, H.N.; Chen, X.; Wang, H. Blockchain challenges and opportunities: A survey. IJWGS 2018, 14, 352. [CrossRef]

51. Su, K.; Li, J.; Fu, H. Smart city and the applications. In International Conference on Electronics, Communications and Control (ICECC); IEEE: Piscataway, NJ, USA, 2011; pp. 1028-1031, ISBN 1457703211.

52. Sokolov, A.; Veselitskaya, N.; Carabias, V.; Yildirim, O. Scenario-based identification of key factors for smart cities development policies. Technol. Forecast. Soc. Chang. 2019, 148, 119729. [CrossRef]

53. Logan, J.R.; Molotch, H. Urban Fortunes: The Political Economy of Place; University of California Press: London, UK, 1987.

54. Yin, C.; Xiong, Z.; Chen, H.; Wang, J.; Cooper, D.; David, B. A literature survey on smart cities. Sci. China Inf. Sci. 2015, 58, 1-18. [CrossRef]

55. Da Silva, W.M.; Alvaro, A.; Tomas, G.H.R.P.; Afonso, R.A.; Dias, K.L.; Garcia, V.C. Smart cities software architectures. In Proceedings of the 28th Annual ACM Symposium on Applied Computing, Coimbra, Portugal, 18-22 March 2013; Shin, S.Y., Maldonado, J.C., Eds.; ACM: New York, NY, USA, 2013; p. 1722, ISBN 9781450316569.

56. Pan, G.; Qi, G.; Zhang, W.; Li, S.; Wu, Z.; Yang, L. Trace analysis and mining for smart cities: Issues, methods, and applications. IEEE Commun. Mag. 2013, 51, 120-126. [CrossRef]

57. Kuk, G.; Janssen, M. The Business Models and Information Architectures of Smart Cities. J. Urban Technol. 2011, 18, 39-52. [CrossRef] 
58. Albino, V.; Berardi, U.; Dangelico, R.M. Smart Cities: Definitions, Dimensions, Performance, and Initiatives. J. Urban Technol. 2015, 22, 3-21. [CrossRef]

59. Bergan, P.; Rehring, K.; Muschkiet, M.; Ahlemann, F.; Hackemann, L. Toward Smart City Architecture Principles: A Cornerstone in the Case of Smart City Duisburg. In Electronic Government and the Information Systems Perspective; Kö, A., Francesconi, E., Kotsis, G., Tjoa, A.M., Khalil, I., Eds.; Springer International Publishing: Cham, Switzerland, 2021; pp. 46-60, ISBN 978-3-030-86610-5.

60. Caragliu, A.; Del Bo, C.; Nijkamp, P. Smart Cities in Europe. J. Urban Technol. 2011, 18, 65-82. [CrossRef]

61. Dameri, R.P.; Ricciardi, F. Leveraging smart city projects for benefitting citizens: The role of ICTs. In Smart City Networks; Springer: Cham, Switzerland, 2017; pp. 111-128.

62. Faulin, J.; Grasman, S.E.; Juan, A.A.; Hirsch, P. (Eds.) Sustainable Transportation and Smart Logistics: Decision-Making Models and Solutions; Elsevier: Amsterdam, The Netherlands, 2019; ISBN 978-0-12-814242-4.

63. Zhang, J.; Wang, F.-Y.; Wang, K.; Lin, W.-H.; Xu, X.; Chen, C. Data-Driven Intelligent Transportation Systems: A Survey. IEEE Trans. Intell. Transport. Syst. 2011, 12, 1624-1639. [CrossRef]

64. Faria, R.; Brito, L.; Baras, K.; Silva, J. Smart mobility: A survey. In Proceedings of the 2017 International Conference on Internet of Things for the Global Community (IoTGC), Funchal, Madeira, 10-13 July 2017.

65. Briner, R.B.; Walshe, N.D. From Passively Received Wisdom to Actively Constructed Knowledge: Teaching Systematic Review Skills as a Foundation of Evidence-Based Management. AMLE 2014, 13, 415-432. [CrossRef]

66. Srivastava, A.; Mukherjee, S.; Jebarajakirthy, C. Aspirational consumption at the bottom of pyramid: A review of literature and future research directions. J. Bus. Res. 2020, 110, 246-259. [CrossRef]

67. Kitchenham, B.; Charters, S. Guidelines for performing Systematic Literature Reviews in Software Engineering: Version 2.3. 2007. Available online: https://userpages.uni-koblenz.de/ \{\}laemmel/esecourse/slides/slr.pdf (accessed on 20 November 2021).

68. Mustak, M.; Salminen, J.; Plé, L.; Wirtz, J. Artificial intelligence in marketing: Topic modeling, scientometric analysis, and research agenda. J. Bus. Res. 2021, 124, 389-404. [CrossRef]

69. Kulkarni, A.V.; Aziz, B.; Shams, I.; Busse, J.W. Comparisons of citations in Web of Science, Scopus, and Google Scholar for articles published in general medical journals. JAMA 2009, 302, 1092-1096. [CrossRef]

70. Mattke, J.; Maier, C.; Reis, L.; Weitzel, T. Bitcoin investment: A mixed methods study of investment motivations. Eur. J. Inf. Syst. 2020, 5, 1-25. [CrossRef]

71. Wohrer, M.; Zdun, U. Smart contracts: Security patterns in the ethereum ecosystem and solidity. In Proceedings of the 2018 International Workshop on Blockchain Oriented Software Engineering (IWBOSE), Campobasso, Italy, 20 March 2018; IEEE: Piscataway, NJ, USA, 2018; pp. 2-8, ISBN 978-1-5386-5986-1.

72. Oliva, G.A.; Hassan, A.E.; Jiang, Z.M. An exploratory study of smart contracts in the Ethereum blockchain platform. Empir. Softw. Eng. 2020, 25, 1864-1904. [CrossRef]

73. Leiding, B.; Memarmoshrefi, P.; Hogrefe, D. Self-managed and blockchain-based vehicular ad-hoc networks. In Proceedings of the 2016 ACM International Joint Conference on Pervasive and Ubiquitous Computing, Heidelberg, Germany, 12-16 September 2016; Lukowicz, P., Krüger, A., Bulling, A., Lim, Y.-K., Patel, S.N., Eds.; ACM: New York, NY, USA, 2016; pp. 137-140, ISBN 9781450344623.

74. Yuan, Y.; Wang, F.-Y. Towards blockchain-based intelligent transportation systems. In Proceedings of the 2016 IEEE 19th International Conference on Intelligent Transportation Systems (ITSC), Rio de Janeiro, Brazil, 1-4 November 2016; IEEE: Piscataway, NJ, USA, 2016; pp. 2663-2668, ISBN 978-1-5090-1889-5.

75. Sharma, P.K.; Moon, S.Y.; Park, J.H. Block-VN: A Distributed Blockchain Based Vehicular Network Architecture in Smart City. J. Inf. Process. Syst. 2017, 13, 184-195. [CrossRef]

76. Lei, A.; Cruickshank, H.; Cao, Y.; Asuquo, P.; Ogah, C.P.A.; Sun, Z. Blockchain-Based Dynamic Key Management for Heterogeneous Intelligent Transportation Systems. IEEE Internet Things J. 2017, 4, 1832-1843. [CrossRef]

77. Lu, Z.; Wang, Q.; Qu, G.; Liu, Z. BARS: A Blockchain-Based Anonymous Reputation System for Trust Management in VANETs. In Proceedings of the 2018 17th IEEE International Conference on Trust, Security and Privacy in Computing and Communications/12th IEEE International Conference on Big Data Science and Engineering (TrustCom/BigDataSE), New York, NY, USA, 1-3 August 2018; IEEE: Piscataway, NJ, USA, 2018; pp. 98-103, ISBN 978-1-5386-4388-4.

78. Wagner, M.; McMillin, B. Cyber-Physical Transactions: A Method for Securing VANETs with Blockchains. In Proceedings of the 2018 IEEE 23rd Pacific Rim International Symposium on Dependable Computing (PRDC), Taipei, Taiwan, 4-7 December 2018; IEEE: Piscataway, NJ, USA, 2018; pp. 64-73, ISBN 978-1-5386-5700-3.

79. Zhang, X.; Wang, D. Adaptive Traffic Signal Control Mechanism for Intelligent Transportation Based on a Consortium Blockchain. IEEE Access 2019, 7, 97281-97295. [CrossRef]

80. Zhang, X.; Chen, X. Data Security Sharing and Storage Based on a Consortium Blockchain in a Vehicular Ad-hoc Network. IEEE Access 2019, 7, 58241-58254. [CrossRef]

81. Aujla, G.S.; Singh, A.; Singh, M.; Sharma, S.; Kumar, N.; Choo, K.-K.R. BloCkEd: Blockchain-Based Secure Data Processing Framework in Edge Envisioned V2X Environment. IEEE Trans. Veh. Technol. 2020, 69, 5850-5863. [CrossRef]

82. Khelifi, H.; Luo, S.; Nour, B.; Moungla, H.; Ahmed, S.H.; Guizani, M. A blockchain-based architecture for secure vehicular Named Data Networks. Comput. Electr. Eng. 2020, 86, 106715. [CrossRef]

83. Malik, N.; Nanda, P.; He, X.; Liu, R.P. Vehicular networks with security and trust management solutions: Proposed secured message exchange via blockchain technology. Wirel. Netw 2020, 26, 4207-4226. [CrossRef] 
84. Raja, G.; Manaswini, Y.; Vivekanandan, G.D.; Sampath, H.; Dev, K.; Bashir, A.K. AI-Powered Blockchain-A Decentralized Secure Multiparty Computation Protocol for IoV. In Proceedings of the IEEE INFOCOM 2020-IEEE Conference on Computer Communications Workshops (INFOCOM WKSHPS), Toronto, ON, Canada, 6-9 July 2020; IEEE: Piscataway, NJ, USA, 2020; pp. 865-870, ISBN 978-1-7281-8695-5.

85. Kudva, S.; Badsha, S.; Sengupta, S.; Khalil, I.; Zomaya, A. Towards secure and practical consensus for blockchain based VANET. Inf. Sci. 2021, 545, 170-187. [CrossRef]

86. Saurabh, N.; Rubia, C.; Palanisamy, A.; Koulouzis, S.; Sefidanoski, M.; Chakravorty, A.; Zhao, Z.; Karadimce, A.; Prodan, R. The ARTICONF Approach to Decentralized Car-Sharing. Blockchain Res. Appl. 2021, 100013. [CrossRef]

87. George, S.A.; Jaekel, A.; Saini, I. Secure Identity Management Framework for Vehicular Ad-hoc Network using Blockchain. In Proceedings of the 2020 IEEE Symposium on Computers and Communications (ISCC), Rennes, France, 7-10 July 2020; IEEE: Piscataway, NJ, USA, 2020; pp. 1-6, ISBN 978-1-7281-8086-1.

88. Yang, Z.; Yang, K.; Lei, L.; Zheng, K.; Leung, V.C.M. Blockchain-Based Decentralized Trust Management in Vehicular Networks. IEEE Internet Things J. 2019, 6, 1495-1505. [CrossRef]

89. Li, L.; Liu, J.; Cheng, L.; Qiu, S.; Wang, W.; Zhang, X.; Zhang, Z. CreditCoin: A Privacy-Preserving Blockchain-Based Incentive Announcement Network for Communications of Smart Vehicles. IEEE Trans. Intell. Transport. Syst. 2018, 19, 2204-2220. [CrossRef]

90. Dubois, A.; Wehenkel, A.; Fonteneau, R.; Olivier, F.; Ernst, D. An App-based Algorithmic Approach for Harvesting Local and Renewable Energy using Electric Vehicles. In Proceedings of the ICAART 2017-9th International Conference on Agents and Artificial Intelligence, Porto, Portugal, 24-26 February 2017; pp. 322-327.

91. Kang, J.; Yu, R.; Huang, X.; Maharjan, S.; Zhang, Y.; Hossain, E. Enabling Localized Peer-to-Peer Electricity Trading Among Plug-in Hybrid Electric Vehicles Using Consortium Blockchains. IEEE Trans. Ind. Inf. 2017, 13, 3154-3164. [CrossRef]

92. Huang, X.; Xu, C.; Wang, P.; Liu, H. LNSC: A Security Model for Electric Vehicle and Charging Pile Management Based on Blockchain Ecosystem. IEEE Access 2018, 6, 13565-13574. [CrossRef]

93. Knirsch, F.; Unterweger, A.; Engel, D. Privacy-preserving blockchain-based electric vehicle charging with dynamic tariff decisions. Comput. Sci. Res. Dev. 2018, 33, 71-79. [CrossRef]

94. Chang, S.E.; Chang, C.-Y. Application of Blockchain Technology to Smart City Service: A Case of Ridesharing. In Proceedings of the 2018 IEEE International Conference on Internet of Things (iThings) and IEEE Green Computing and Communications (GreenCom) and IEEE Cyber, Physical and Social Computing (CPSCom) and IEEE Smart Data (SmartData), Halifax, NS, Canada, 30 July-3 August 2018; IEEE: Piscataway, NJ, USA, 2018; pp. 664-671, ISBN 978-1-5386-7975-3.

95. Baza, M.; Lasla, N.; Mahmoud, M.M.; Srivastava, G.; Abdallah, M. B-Ride: Ride Sharing with Privacy-preservation, Trust and Fair Payment atop Public Blockchain. IEEE Trans. Netw. Sci. Eng. 2019, 8, 1214-1229. [CrossRef]

96. Khanji, S.; Assaf, S. Boosting Ridesharing Efficiency Through Blockchain: GreenRide Application Case Study. In Proceedings of the 2019 10th International Conference on Information and Communication Systems (ICICS), Irbid, Jordan, 11-13 June 2019; IEEE: Piscataway, NJ, USA, 2019; pp. 224-229, ISBN 978-1-7281-0045-6.

97. Nguyen, T.H.; Partala, J.; Pirttikangas, S. Blockchain-Based Mobility-as-a-Service. In Proceedings of the 2019 28th International Conference on Computer Communication and Networks (ICCCN), Valencia, Spain, 29 July-1 August 2019; IEEE: Piscataway, NJ, USA, 2019; pp. 1-6, ISBN 978-1-7281-1856-7.

98. Semenko, Y.; Saucez, D. Distributed Privacy Preserving Platform for Ridesharing Services. In Proceedings of the 12th International Conference on Security, Privacy, and Anonymity in Computation, Communication, and Storage, Atlanta, GA, USA, 14-17 July 2019; Wang, G., Feng, J., Bhuiyan, M.Z.A., Eds.; Springer International Publishing: Cham, Switzerland, 2019; pp. 1-14, ISBN 9783-030-24907-6.

99. Valaštín, V.; Kost'al, K.; Bencel, R.; Kotuliak, I. Blockchain Based Car-Sharing Platform. In Proceedings of the 2019 International Symposium ELMAR, Zadar, Croatia, 23-25 September 2019; IEEE: Piscataway, NJ, USA, 2019; pp. 5-8, ISBN 978-1-7281-2181-9.

100. Zhang, X.; Liu, J.; Li, Y.; Cui, Q.; Tao, X.; Liu, R.P. Blockchain Based Secure Package Delivery via Ridesharing. In Proceedings of the 2019 11th International Conference on Wireless Communications and Signal Processing (WCSP), Xi'an, China, 23-25 October 2019; IEEE: Piscataway, NJ, USA, 2019; pp. 1-6, ISBN 978-1-7281-3555-7.

101. Abubaker, Z.; Gurmani, M.U.; Sultana, T.; Rizwan, S.; Azeem, M.; Iftikhar, M.Z.; Javaid, N. Decentralized Mechanism for Hiring the Smart Autonomous Vehicles Using Blockchain. In Advances on Broad-Band Wireless Computing, Communication and Applications; Barolli, L., Hellinckx, P., Enokido, T., Eds.; Springer International Publishing: Cham, Switzerland, 2020; pp. 733-746, ISBN 978-3-030-33505-2.

102. Gudymenko, I.; Khalid, A.; Siddiqui, H.; Idrees, M.; ClauB, S.; Luckow, A.; Bolsinger, M.; Miehle, D. Privacy-Preserving Blockchain-Based Systems for Car Sharing Leveraging Zero-Knowledge Protocols. In Proceedings of the 2020 IEEE International Conference on Decentralized Applications and Infrastructures (DAPPS), Oxford, UK, 3-6 August 2020; IEEE: Piscataway, NJ, USA, 2020; pp. 114-119, ISBN 978-1-7281-6978-1.

103. Palanisamy, A.; Sefidanoski, M.; Koulouzis, S.; Rubia, C.; Saurabh, N.; Prodan, R. Decentralized Social Media Applications as a Service: A Car-Sharing Perspective. In Proceedings of the 2020 IEEE Symposium on Computers and Communications (ISCC), Rennes, France, 7-10 July 2020; IEEE: Piscataway, NJ, USA, 2020; pp. 1-7, ISBN 978-1-7281-8086-1.

104. Zhou, Q.; Yang, Z.; Zhang, K.; Zheng, K.; Liu, J. A Decentralized Car-Sharing Control Scheme Based on Smart Contract in Internet-of-Vehicles. In Proceedings of the 2020 IEEE 91st Vehicular Technology Conference (VTC2020-Spring), Antwerp, Belgium, 25-28 May 2020; IEEE: Piscataway, NJ, USA, 2020; pp. 1-5, ISBN 978-1-7281-5207-3. 
105. Ying, Z.; Yi, L.; Ma, M. BEHT: Blockchain-Based Efficient Highway Toll Paradigm for Opportunistic Autonomous Vehicle Platoon. Wirel. Commun. Mob. Comput. 2020, 2020, 8868656. [CrossRef]

106. Chen, C.; Xiao, T.; Qiu, T.; Lv, N.; Pei, Q. Smart-Contract-Based Economical Platooning in Blockchain-Enabled Urban Internet of Vehicles. IEEE Trans. Ind. Inf. 2020, 16, 4122-4133. [CrossRef]

107. Ji, Y.; Hou, R.; Lui, K.-S.; Li, H. A Blockchain-Based Vehicle Platoon Leader Updating Scheme. In Proceedings of the ICC 2020-2020 IEEE International Conference on Communications (ICC), Dublin, Ireland, 7-11 June 2020; IEEE: Piscataway, NJ, USA, 2020; pp. 1-6, ISBN 978-1-7281-5089-5.

108. Ying, Z.; Ma, M.; Yi, L. BAVPM: Practical Autonomous Vehicle Platoon Management Supported by Blockchain Technique. In Proceedings of the 2019 4th International Conference on Intelligent Transportation Engineering (ICITE), Singapore, 5-7 September 2019; IEEE: Piscataway, NJ, USA, 2019; pp. 256-260, ISBN 978-1-7281-4553-2.

109. Ogundoyin, S.O. An autonomous lightweight conditional privacy-preserving authentication scheme with provable security for vehicular ad-hoc networks. Int. J. Comput. Appl. 2020, 42, 196-211. [CrossRef]

110. He, D.; Zeadally, S.; Xu, B.; Huang, X. An Efficient Identity-Based Conditional Privacy-Preserving Authentication Scheme for Vehicular Ad Hoc Networks. IEEE Trans. Inform. Forensic Secur. 2015, 10, 2681-2691. [CrossRef]

111. Dai Nguyen, H.P.; Zoltan, R. The Current Security Challenges of Vehicle Communication in the Future Transportation System. In Proceedings of the 2018 IEEE 16th International Symposium on Intelligent Systems and Informatics (SISY), Subotica, Serbia, 13-15 September 2018; IEEE: Piscataway, NJ, USA, 2018; pp. 161-166, ISBN 978-1-5386-6841-2.

112. Almasoud, A.S.; Eljazzar, M.M.; Hussain, F. Toward a Self-Learned Smart Contracts. In Proceedings of the 15th International Conference on E-Business Engineering, Xi'an, China, 12-14 October 2018; IEEE Computer Society: Los Alamitos, CA, USA; Conference Publishing Services: Tokyo, Japan, 2018; pp. 269-273, ISBN 978-1-5386-7992-0.

113. Nguyen, H.; Bailey, S. Use of Artificial Intelligence for Smart Contracts and Blockchains. FinTechLaw Rep. E-Bank. Paym. Commer. Mob. World 2018, 20, 1-7.

114. Singh, H.J.; Hafid, A.S. Prediction of Transaction Confirmation Time in Ethereum Blockchain Using Machine Learning. In Blockchain and Applications: International Congress; Prieto, J., Das, A.K., Ferretti, S., Pinto, A., Corchado, J.M., Eds.; Springer: Cham, Switzerland, 2020; pp. 126-133, ISBN 978-3-030-23812-4.

115. Chen, J.; Duan, K.; Zhang, R.; Zeng, L.; Wang, W. An AI Based Super Nodes Selection Algorithm in BlockChain Networks. 2018. Available online: http:/ / arxiv.org/pdf/1808.00216v1 (accessed on 26 November 2021).

116. Kim, S. Impacts of Mobility on Performance of Blockchain in VANET. IEEE Access 2019, 7, 68646-68655. [CrossRef]

117. Crain, T.; Gramoli, V.; Larrea, M.; Raynal, M. DBFT: Efficient Byzantine Consensus with a Weak Coordinator and its Application to Consortium Blockchains. Available online: http:/ / arxiv.org/pdf/1702.03068v3 (accessed on 26 November 2021).

118. Lin, J.; Yu, W.; Zhang, N.; Yang, X.; Zhang, H.; Zhao, W. A Survey on Internet of Things: Architecture, Enabling Technologies, Security and Privacy, and Applications. IEEE Internet Things J. 2017, 4, 1125-1142. [CrossRef]

119. Ekedebe, N.; Lu, C.; Yu, W. Towards experimental evaluation of intelligent Transportation System safety and traffic efficiency. In Proceedings of the 2015 IEEE International Conference on Communications (ICC), London, UK, 8-12 June 2015; IEEE: Piscataway, NJ, USA, 2015; pp. 3757-3762, ISBN 978-1-4673-6432-4.

120. Botsman, R.; Rogers, R. What's Mine Is Yours: The Rise of Collaborative Consumption, 1st ed.; Harper Business: New York, NY, USA, 2010; ISBN 9780061963544.

121. Prodan, R.; Saurabh, N.; Zhao, Z.; Orton-Johnson, K.; Chakravorty, A.; Karadimce, A.; Ulisses, A. ARTICONF: Towards a Smart Social Media Ecosystem in a Blockchain Federated Environment. In Euro-Par 2019: Parallel Processing Workshops; Schwardmann, U., Boehme, C., Heras, D.B., Cardellini, V., Jeannot, E., Salis, A., Schifanella, C., Manumachu, R.R., Schwamborn, D., Ricci, L., et al., Eds.; Springer International Publishing: Cham, Switzerland, 2020; pp. 417-428, ISBN 978-3-030-48339-5.

122. Bhoopalam, A.K.; Agatz, N.; Zuidwijk, R. Planning of truck platoons: A literature review and directions for future research. Transp. Res. Part B Methodol. 2018, 107, 212-228. [CrossRef]

123. Patten, J.; McAuliffe, B.; Mayda, W.; Tanguay, B. Review of Aerodynamic Drag Reduction Devices for Heavy Trucks and Buses: Technical Report. Available online: https://www.tc.gc.ca/en/programs-policies/programs/documents / AERODYNAMICS_ REPORT-MAY_2012.pdf (accessed on 26 January 2020).

124. Zabat, M.; Stabile, N.; Frascaroli, S.; Browand, F. The Aerodynamic Performance of Platoons: Final Report: Technical Report; University of California: Berkeley, CA, USA, 1995.

125. Scora, G.; Barth, M. Comprehensive Modal Emissions Model (CMEM), Version 3.01: User Guide; Centre for Environmental Research and Technology, University of California: Riverside, CA, USA, 2006.

126. Shladover, S.E.; Nowakowski, C.; Lu, X.-Y.; Ferlis, R. Cooperative Adaptive Cruise Control. Transp. Res. Rec. 2015, $2489,145-152$. [CrossRef]

127. Van Arem, B.; van Driel, C.J.G.; Visser, R. The Impact of Cooperative Adaptive Cruise Control on Traffic-Flow Characteristics. IEEE Trans. Intell. Transport. Syst. 2006, 7, 429-436. [CrossRef]

128. Lioris, J.; Pedarsani, R.; Tascikaraoglu, F.Y.; Varaiya, P. Platoons of connected vehicles can double throughput in urban roads. Transp. Res. Part C Emerg. Technol. 2017, 77, 292-305. [CrossRef]

129. Ma, Y.; Wang, J. A Study on Economical Vehicle Platooning Strategy in Urban Driving Scenarios. In Proceedings of the 2018 IEEE Vehicle Power and Propulsion Conference (VPPC), Chicago, IL, USA, 27-30 August 2018; IEEE: Piscataway, NJ, USA, 2018; pp. 1-6, ISBN 978-1-5386-6203-8. 
130. Subramanian, H. Decentralized blockchain-based electronic marketplaces. Commun. ACM 2017, 61, 78-84. [CrossRef]

131. Kabi, O.R.; Franqueira, V.N.L. Blockchain-Based Distributed Marketplace. In Business Information Systems Workshops; Abramowicz, W., Paschke, A., Eds.; Springer International Publishing: Cham, Switzerland, 2019; pp. 197-210, ISBN 978-3-030-04848-8.

132. Özyılmaz, K.R.; Doğan, M.; Yurdakul, A. IDMoB: IoT Data Marketplace on Blockchain. In Proceedings of the 2018 Crypto Valley Conference on Blockchain Technology, Zug, Switzerland, 20-22 June 2018; Conference Publishing Services: Tokyo, Japan; IEEE Computer Society: Los Alamitos, CA, USA, 2018; pp. 11-19, ISBN 978-1-5386-7204-4.

133. Wang, Y.; Samavi, R.; Sood, N. Blockchain-based Marketplace for Software Testing. In Proceedings of the 2019 17th International Conference on Privacy, Security and Trust (PST), Fredericton, NB, Canada, 26-28 August 2019; IEEE: Piscataway, NJ, USA, 2019; pp. 1-3, ISBN 978-1-7281-3265-5.

134. Leduc, G.; Kubler, S.; Georges, J.-P. Innovative blockchain-based farming marketplace and smart contract performance evaluation. J. Clean. Prod. 2021, 306, 127055. [CrossRef]

135. Hawlitschek, F.; Notheisen, B.; Teubner, T. The limits of trust-free systems: A literature review on blockchain technology and trust in the sharing economy. Electron. Commer. Res. Appl. 2018, 29, 50-63. [CrossRef]

136. Garaus, M.; Treiblmaier, H. The influence of blockchain-based food traceability on retailer choice: The mediating role of trust. Food Control 2021, 129, 108082. [CrossRef]

137. Ter Huurne, M.; Ronteltap, A.; Corten, R.; Buskens, V. Antecedents of trust in the sharing economy: A systematic review. $J$ Consum. Behav 2017, 16, 485-498. [CrossRef]

138. Treiblmaier, H.; Swan, M.; de Filippi, P.; Lacity, M.; Hardjono, T.; Kim, H. What's Next in Blockchain Research? SIGMIS Database 2021, 52, 27-52. [CrossRef]

139. Hengstler, M.; Enkel, E.; Duelli, S. Applied artificial intelligence and trust-The case of autonomous vehicles and medical assistance devices. Technol. Forecast. Soc. Chang. 2016, 105, 105-120. [CrossRef]

140. Zamani, E.; He, Y.; Phillips, M. On the Security Risks of the Blockchain. J. Comput. Inf. Syst. 2020, 60, 495-506. [CrossRef]

141. Encalada, L.; Boavida-Portugal, I.; Cardoso Ferreira, C.; Rocha, J. Identifying Tourist Places of Interest Based on Digital Imprints: Towards a Sustainable Smart City. Sustainability 2017, 9, 2317. [CrossRef]

142. Zyskind, G.; Nathan, O.; Pentland, A. Decentralizing Privacy: Using Blockchain to Protect Personal Data. In Proceedings of the 2015 IEEE Security and Privacy Workshops, San Jose, CA, USA, 21-22 May 2015; IEEE: Piscataway, NJ, USA, 2015; pp. 180-184, ISBN 978-1-4799-9933-0.

143. Sreehari, P.; Nandakishore, M.; Krishna, G.; Jacob, J.; Shibu, V.S. Smart will converting the legal testament into a smart contract. In Proceedings of the 2017 International Conference on Networks \& Advances in Computational Technologies (NetACT), Thiruvanthapuram, India, 20-22 July 2017; IEEE: Piscataway, NJ, USA, 2017; pp. 203-207, ISBN 978-1-5090-6590-5.

144. Huertas, A.; Moreno, A.; Pascual, J. Place Branding for Smart Cities and Smart Tourism Destinations: Do They Communicate Their Smartness? Sustainability 2021, 13, 10953. [CrossRef]

145. Neuhofer, B.; Buhalis, D.; Ladkin, A. Smart technologies for personalized experiences: A case study in the hospitality domain. Electron Mark. 2015, 25, 243-254. [CrossRef]

146. Boes, K.; Buhalis, D.; Inversini, A. Smart tourism destinations: Ecosystems for tourism destination competitiveness. Int. J. Tour. Cities 2016, 2, 108-124. [CrossRef]

147. Koo, C.; Joun, Y.; Han, H.; Chung, N. The Impact of Potential Travellers' Media Cultural Experiences. In Information and Communication Technologies in Tourism 2014; Xiang, Z., Tussyadiah, I., Eds.; Springer International Publishing: Cham, Switzerland, 2013; pp. 579-592, ISBN 978-3-319-03972-5.

148. Gretzel, U.; Zhong, L.; Koo, C. Application of smart tourism to cities. Int. J. Tour. Cities 2016, 2. [CrossRef]

149. Albalate, D.; Bel, G. Tourism and urban public transport: Holding demand pressure under supply constraints. Tour. Manag. 2010, 31, 425-433. [CrossRef]

150. Voss, W.G. Data Protection Issues for Smart Contracts. In Smart Contracts; Compagnucci, M.C., Fenwick, M., Wrbka, S., Eds.; Hart Publishing: Oxford, UK, 2021; ISBN 978-1-50993-702-8.

151. Voss, W.G.; Bouthinon-Dumas, H. EU General Data Protection Regulation Sanctions in Theory and in Practice. St. Clara High Technol. Law J. 2021, 37, 1.

152. Voss, W.G. The CCPA and the GDPR Are Not the Same: Why You Should Understand Both. CPI Antitrust Chron. 2021, 1, 7-12.

153. Park, J.Y.; Sung, C.S. A business model analysis of blockchain technology-based startup. JESI 2020, 7, 3048-3060. [CrossRef]

154. Limba, T.; Stankevičius, A.; Andrulevičius, A. Cryptocurrency as disruptive technology: Theoretical insights. JESI 2019, 6, 2068-2080. [CrossRef]

155. Buterin, V. Ethereum White Paper: A Next-Generation Smart Contract and Decentralized Application Platform. 2013. Available online: https://www.blockchainresearchnetwork.org/research/whitepapers/ (accessed on 20 August 2019).

156. Chohan, U.W. The Decentralized Autonomous Organization and Governance Issues. SSRN Electron. J. 2017. [CrossRef]

157. Snyder, H. Literature review as a research methodology: An overview and guidelines. J. Bus. Res. 2019, 104, 333-339. [CrossRef]

158. Webster, J.; Watson, R.T. Analyzing the Past to Prepare for the Future: Writing a Literature Review. Manag. Inf. Syst. Q. 2002, $26,13$.

159. Vom Brocke, J.; Hevner, A.; Maedche, A. Introduction to Design Science Research. In Design Science Research. Cases; Springer: Cham, Switzerland, 2020; pp. 1-13. 
160. Vom Brocke, J.; Maedche, A. The DSR grid: Six core dimensions for effective capturing of DSR projects. Electron. Mark. 2019, 29, 379-385. [CrossRef]

161. Gregor, S.; Hevner, A.R. Positioning and presenting design science research for maximum impact. MIS Q. 2013, 37, 337-355. [CrossRef] 